\title{
A Vitreoretinal Surgery System Fluidics Failure Modes and Effects Analysis
}

\author{
A Thesis Presented to the Faculty of \\ California Polytechnic State University \\ San Luis Obispo, CA
}

\begin{abstract}
In Partial Fulfillment of the Requirements for the Degree

Master of Science in Engineering with a Specialization in Biomedical Engineering
\end{abstract}

Jennifer Ann Grega June 2008 


\section{AUTHORIZATION FOR REPRODUCTION OF MASTER'S THESIS}

I grant permission for the reproduction of this thesis in its entirety or any of its parts, without further authorization from me.

- ii - 


\section{APPROVAL PAGE}

TITLE: A Vitreoretinal Surgery System Fluidics Failure Mode and Effects Analysis

\section{AUTHOR: Jennifer Ann Grega}

DATE SUBMITTED: June 5, 2008

Dr. Robert Crockett

Advisor and Committee Chair

Dr. Dan Walsh

Committee Member

Dr. Robert Szlavik

Committee Member

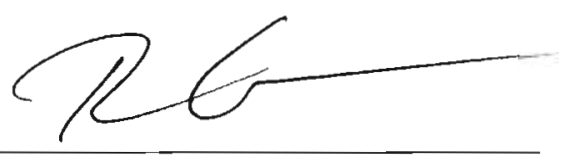

Signature

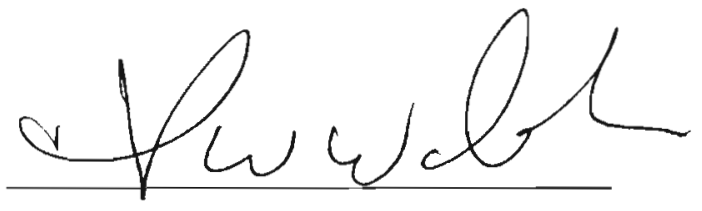

Signature

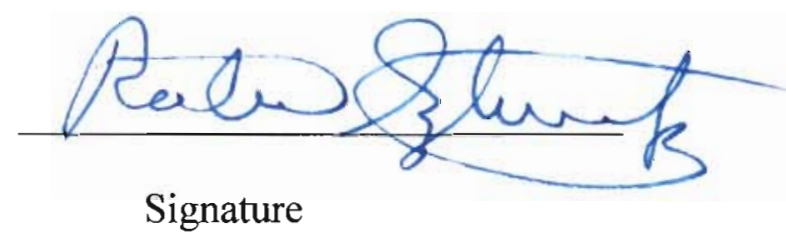




\begin{abstract}
$\underline{\text { Abstract }}$
A Vitreoretinal Surgery System Fluidics Failure Modes and Effects Analysis Jennifer Grega
\end{abstract}

Eyesight is something that is vital to all human beings. The concept of vitreoretinal surgery is an amazing achievement of modern medicine to help treat patients that might otherwise be blind. Vitreoretinal surgery has enhanced and restored vision in numerous individuals due to the forefront of new instrumentation and surgical techniques. As a manufacturer of surgical equipment it is critical that an in depth analysis of potential failure modes is completed and the necessary mitigations are put in place. A complete failure mode and effects analysis on the fluidics sub-module of a vitreoretinal surgery system is an imperative part to new product development. 


\section{Acknowledgements}

\section{California Polytechnic University, San Luis Obispo, California}

Thesis Advisor:

- Dr. Robert Crockett

Thesis Committee:

- Dr. Dan Walsh

- Dr. Robert Szlavik 


\section{$\underline{\text { Table of Contents }}$}

List of Tables...................................................... vii

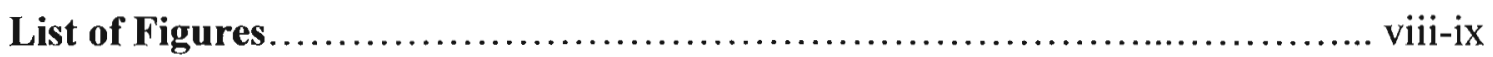

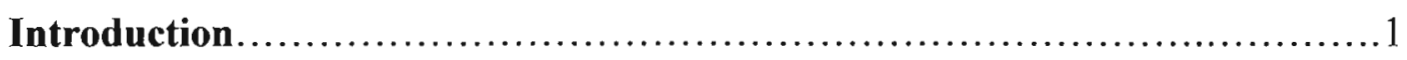

Human and Economic Importance..................................... 1

Literature Review.................................................... 2

Eye Anatomy and Physiology .................................... 2

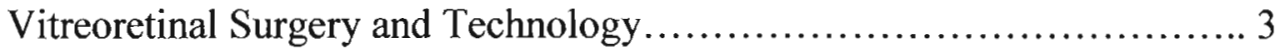

Failure Modes and Effects Analysis................................... 4

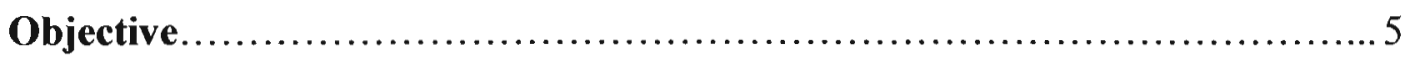

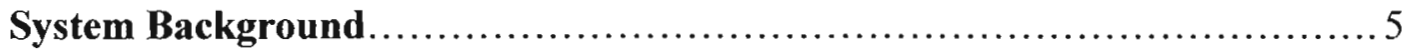

Procedure...............................................................

Failure Modes and Effects Analysis Data.............................. 11

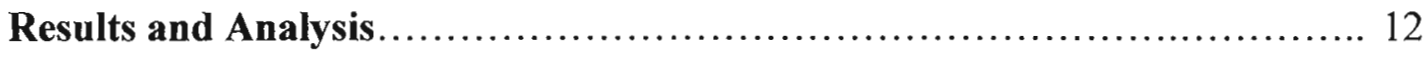

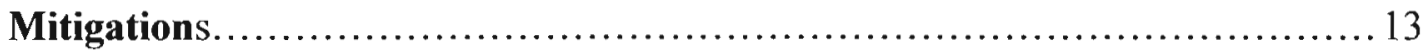

Discussion............................................................ 14

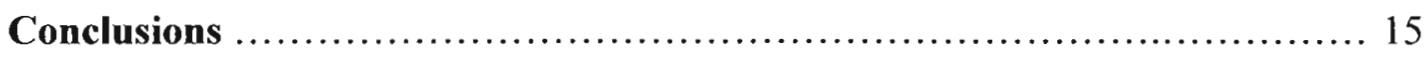

Discussion for Future Work .......................................... 15

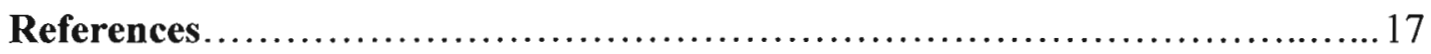

Appendices

I: $\quad$ Human Eye Anatomy and Physiology...........................21

II: $\quad$ Vitreoretinal Surgery Background............................... 42

III: $\quad$ Failure Mode and Effect Analysis Background.....................62

IV: $\quad$ Fluidics Failure Mode and Effect Analysis..................... 80 


\section{List of Tables}

Table 1: Summary of the FMEA entries based on fluidics sub-modules........... 11

Table 2: Summary table of required mitigations............................. 13

Table 3: The twelve key elements of the FMEA process........................6 65

Table 4: The layout of a sample FMEA table................................ 71

Table 5: The ratings for the severity of a potential failure mode................. 73

Table 6: Guidelines for severity rankings for a process and/or service FMEA.....74

Table 7: The description for the occurrence ratings for a potential failure mode....75

Figure 8: Guidelines for occurrence rankings for a process and/or service FMEA..76

Table 9: The criteria for the ratings of the diction for a potential failure mode... 77

Table 10: Guidelines for detection rankings for a process and/or service FMEA...78 


\section{$\underline{\text { List of Figures }}$}

Figure 1: Anatomy of human eye from NIH National Eye Institute................ 22

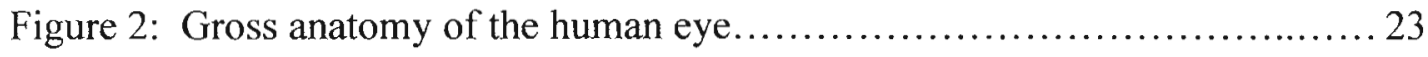

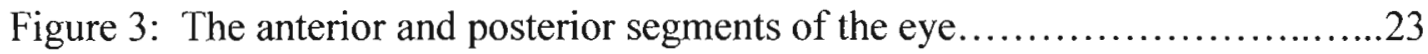

Figure 4: The fluids in each segment of the eye............................. 24

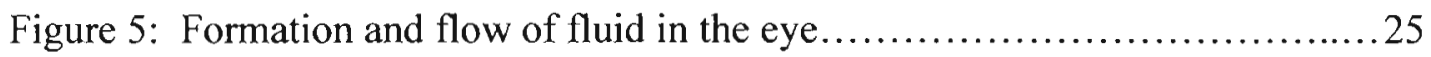

Figure 6: The sclera and cornea...................................... 26

Figure 7: Locations of the sclera and conjunctiva........................... 27

Figure 8: The blood vessels in the choroid.................................. 27

Figure 9: The structures of the uveal tract.............................. 28

Figure 10: Diagram showing the location of the retina and the optic nerve........29

Figure 11: Relative positions of the anatomical structures of the eye's interior..... 30

Figure 12: The cornea................................................ 30

Figure 13: Innervation of the corneal surface by nerve endings from the fifth

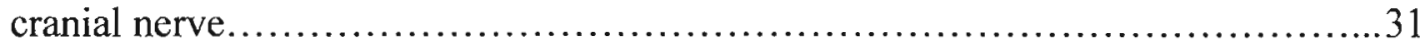

Figure 14: Diagram of corneal epithelial cells............................. 32

Figure 15: The precorneal tear film...................................... 33

Figure 16: A diagram of the pupil....................................... 33

Figure 17: Detailed side and front view of the iris and pupil .................. 34

Figure 18: The shape of the lens showing objects in focus................... 35

Figure 19: The three main layers of the retina............................. 37

Figure 20: The layers of the retina showing the cells and photoreceptors.......... 37

Figure 21: The neural organization of the retina............................. 38

Figure 22: A microscopic view of rods and cones............................ 38 
Figure 23: Schematic drawing of the functional parts of the rods and cones

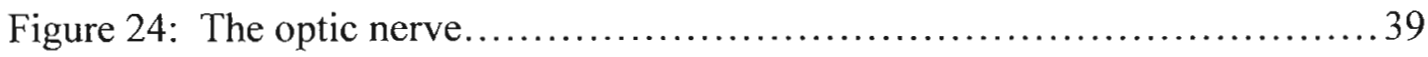

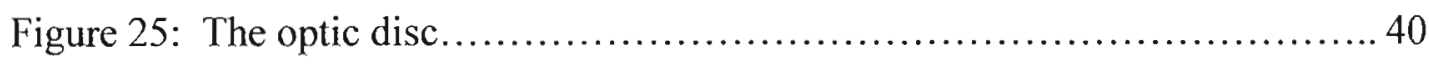

Figure 26: Vasoconstriction and vasodilation.............................40

Figure 27: The sources of blood supply for the retina....................... 40

Figure 28: A surgeon's view during vitreoretinal surgery $\ldots \ldots \ldots \ldots \ldots \ldots \ldots \ldots . \ldots 43$

Figure 29: A diagram of the scleral buckling procedure...................... 46

Figure 30: Vitreoretinal surgery instruments entering the eye through the pars

plana in order to remove the vitreous...................................... 46

Figure 31: Three incisions or sclerotomies used for posterior segment surgery ..... 47

Figure 32: Membrane cutting with intraocular scissors.......................48

Figure 33: A cross section of the eye with a retinal detachment................... 50

Figure 34: Normal vision and the same scene as viewed by a person with age-related macular degeneration......................................... 52

Figure 35: A drawing of proliferative diabetic retinopathy..................... 54

Figure 36: A color retinal photograph centered on the optic nerve demonstrating proliferative diabetic retinopathy and neovascularization........................ 54

Figure 37: A diagram of a macular hole with the patient in the face up position on the left and in the face down position on the right..........................57 


\section{$\underline{\text { Introduction }}$}

For my California Polytechnic State University, San Luis Obispo, California, graduate thesis project the ophthalmic industry was of particular interest to me because it is an area that affects all human beings, if not directly, then indirectly through a family member or a friend. I come from an entire family that wears contacts or glasses and I have three grandparents who have had cataract surgery. Furthermore, I have personally experienced laser corrective surgery myself after suffering countless years with poor eyesight. Through my thesis I have learned a great deal about not only the ophthalmic industry, but also the biomedical engineering industry as a whole.

\section{Human and Economic Importance}

Good eyesight is something that is and always will be vital to all human beings. Most human beings can only imagine what it would be like not to have the ability to see the vibrant world around them. The area of ophthalmology is a growing area that is important today as it will always be. Currently there are a great deal of resources invested in the research and development of new ophthalmic technology with the goal to protect, improve, and restore vision. With the aging population and complications in eyesight there will always be ophthalmic research that needs to be further advanced. The ophthalmic technology has advanced dramatically over the past several years and the future for the improvement of eye care looks promising. 


\section{$\underline{\text { Literature Review }}$}

In order to successfully understand a Failure Mode and Effect Analysis on the fluidics module of a vitreoretinal surgery system it is important to have a basic understanding of human eye anatomy and physiology, vitreoretinal surgery, and Failure Mode and Effect Analyses.

\section{Eye Anatomy and Physiology}

The most fundamental human sense is vision. Vision is the process through which light reflected from objects in the environment is translated into a mental image. Vision is remarkable in terms that it allows individuals to make identifications based on shapes, colors, and sizes along with detecting the movement of objects and the recognition of objects. The human eye can distinguish minuscule variations in shape, color, brightness, and distance and is specialized for the detection, localization, and analysis of light. Human vision is incredible due to the fact it detects things small and large along with things near and far. It is not easy for most human beings to imagine what it would be like to live without the sense of sight and is something that should certainly not be taken for advantage. A detailed description of relevant human eye anatomy and physiology can be seen in Appendix I.

After having a basic understanding of the anatomy of the eye and how the process of vision works the concepts and techniques of vitreoretinal surgery can be more easily understood. 


\section{Vitreoretinal Surgery and Technology}

The development of vitreoretinal surgery occurred during the last three decades of the twentieth century. A large number of patients were unfortunately blinded by inoperable diseases prior to the development of vitreoretinal surgery [22]. The concept of vitreoretinal surgery is an amazing achievement of modern medicine that helps treat patients who might otherwise be blind. Vitreoretinal surgery has enhanced and restored vision in numerous individuals due to the forefront of new instrumentation and surgical techniques.

There is a wide array of reasons that vitreoretinal surgery is necessary and diseases that vitreoretinal surgery is used to treat. No matter the reason vitreoretinal surgery is required the overall goal of vitreoretinal surgery is to restore and enhance vision. An in depth description of the background to vitreoretinal surgery and the various reasons it needs to be performed can be seen in Appendix II. By understanding the basic concepts of vitreoretinal surgery an individual can have a great appreciation for the complicated and intricate surgery equipment that is required.

Today there are many vitreoretinal diseases that were previously untreatable that can be managed through the advancements in vitreoretinal surgery. The study of vitreoretinal disease is fascinating and has a major impact on visual outcomes. New technologies and techniques are being developed at explosive pace and producing great improvements in the outcomes after vitreoretinal surgery [22]. Vitreoretinal surgery is a widely used ophthalmic surgical procedure with applications that are continuing to grow.

Therefore, in order for vitreoretinal surgeons to easily and accurately perform intricate retinal and vitreous surgeries it is extremely important that they have the 
equipment they need that is easy to use and is highly reliable and as error proof as possible. Therefore, before a company can put medical equipment in the market it is crucial that all of the chances for failure and complication have thoroughly been analyzed.

\section{Failure Mode and Effect Analysis}

A Failure Mode and Effect Analysis, or FMEA, is a common tool used widely throughout the engineering industry. "The purpose of a FMEA assessment is to collectively evaluate potential failure modes, ensure adequate controls are in place, prioritize any necessary corrective actions, and documents the evaluation process" [46]. The causes of failure can be identified and eliminated with the sequential and disciplined approach of a Failure Mode and Effect Analysis. Furthermore, another definition of a FMEA is, "a systematic method of identifying and preventing product and process problems before they occur. FMEAs are fully focused on preventing defects, enhancing safety, and increasing customer satisfaction" [41].

A Failure Mode and Effect Analysis is a detailed and complicated procedure. A complete description of the FMEA process and examples can be seen in Appendix III. A complete FMEA a Vitreoretinal System is a critical part to the development and testing of the surgical device which has a large part in the success of the product and the company. 


\section{Objective Statement}

Perform a complete Failure Mode and Effect Analysis for a vitreoretinal surgery system fluidics module which is used for both posterior and anterior eye segment surgeries.

\section{System Background}

The development of vitreoretinal surgery has seen astounding progress over the last century. There have been many technological upgrades to the instruments that are used during vitreoretinal surgery. The main goal for a vitreoretinal surgery is to achieve the best outcome with the least possible surgical intervention. A vitreoretinal surgery system is used primarily on patients with retina and vitreous problems. However, in addition to posterior segment surgery the medical instrument has the capabilities for anterior surgery and combined surgeries.

The medical instrument is a surgical system with maximum control that is very easy to use. The features and controls are easily accessed through an icon-driven surgery screen. With the touch of the screen instant surgical control can be obtained. The medical instrument's technology makes anterior, posterior, and combined surgeries easier and more efficient.

The features and the controls of the medical instrument are accessed through the LCD screen that is driven by the touch of icons. Furthermore, voice commands and confirmation assure that the doctor is in control. The surgeon has the capability of customizing parameter presets for the maximum effectiveness and efficiency. 
There are a total of over 960 components that make up an entire vitreoretinal surgery system unit. Furthermore, there are a total of approximately fifty sub-assemblies in one unit and over forty printed circuit boards depending on the different options available. These numbers themselves show the complexity of the system, not to mention the advanced technology and engineering concepts involved.

The fluidics system of a vitreoretinal surgery system is exquisite. The fluidics sub-module is the most complicated and can be considered the heart of the instrument due to its important functions and capabilities. There are eleven sub-modules that make up the top level fluidics assembly. In total there are 333 components that together make up the fluidics sub-module, which once again gives an idea of the complexity of the submodule.

\section{$\underline{\text { Procedure }}$}

One particular area where Failure Mode and Effect Analyses are extremely critical is the biomedical engineering industry. With the rapid changes in technology, new product development has become a large area of biomedical engineering. Before new surgical equipment can be released into the market there are numerous stages of research and development, testing, and modifications that go into the product design and development. It is important to think of all potential failure issues and take them into consideration in order to make sure all of the design details are correct in order to reduce the risk of assembly and potential failures. Thus, when the product is released in the market a minimal amount of problems occur, and there is the least amount of risk as 
possible to the patient and surgeon. A major component to new product development is Failure Mode and Effect Analysis or FMEA.

Completing the vitreoretinal surgery system fluidics sub-module Failure Mode and Effect Analysis was an extremely challenging and in depth process due to the complexity of the entire system and specifically the fluidics system. In order to successfully make sure that all of the necessary items were included in the FMEA, a great deal of background research was completed along with an in depth study of how the fluidics system works. Learning about the fluidics sub-module required interfacing with the Research and Development engineers who designed the mechanics and new technology behind the system. In addition, a clear understanding of the Theory of Operations was important.

The fluidics FMEA follows a standard operating procedure, or SOP, for completing an assembly FMEA. The SOP described the purpose and procedure of a FMEA. In addition, the SOP provided a detailed example for guidance. It was important to understand the purpose and goals of a FMEA before determining the potential failure modes. The first stage was clearly defining the scope of the project. The overall goal was to complete an assembly process FMEA for the entire fluidics module of the medical instrument by breaking the fluidics module into the eleven smaller sub-modules.

To complete the FMEA for the fluidics sub-assembly of the vitreoretinal surgery system, the assembly drawings for all of the smaller fluidics sub-modules were analyzed step by step. There were a total of eleven fluidics sub-assemblies included in the FMEA in addition to the top level assembly. After looking at the drawings the immense number 
of components that go into a fluidics module can be seen along with the detail and complexity in the system.

Before the potential failure modes were entered into the FMEA it was important to understand necessary considerations to take into account. The first consideration was assembly issues and any potential problems that may arise during the assembly procedure. In addition, any special fixtures or areas with tight tolerances or adjustments were identified. When completing the FMEA it was also important to keep Field Service in mind. Special tools needed and addressing how territory managers could assemble and test the fluidics module in the field were noted. Even though there may not be an issue with assembling a certain part in manufacturing, the same assembly may be extremely difficult in the field without the proper tools and drawings. Lastly, it was important to make sure that all of the key fluidics characteristics were included in the FMEA. Keeping these considerations into account, potential failure modes could be identified for all stages of the fluidics assembly.

There were guidelines that had to be formulated to make sure that there was consistency in what was included as potential failure mode entries. When completing the fluidics assembly FMEA it was assumed that all of the parts were made to specifications. The required parts go through necessary inspections verifying there were no errors in the machining by the supplier. Therefore, all of the dimensions and tolerances were assumed to be correct and any potential failure modes resulting from parts not to specifications were not included in the FMEA.

In addition, another area of importance was to clarify that it was assumed that the printed circuit boards, or PCBs, were made to specification. Therefore, there were no 
electrical potential failure modes that were entered in the FMEA based upon a faulty PCB. When the PCBs were designed all potential failure modes were taken into consideration. For example, PCBs with multiple cable connections were designed to have different sized connectors or keyed connectors in all places possible. However, failure modes due to the incorrect assembly of orientation cables were entered into the FMEA.

Furthermore, when thinking about potential failure modes to put in the FMEA, a great deal of thought had to go into what should be included as far as missing components. A line item for a missing part could be entered for all of the parts in the entire fluidics system which totals over 300 components. However, only the parts that had a high significance if they were missed or parts that had a high likelihood of being missed were entered into the FMEA. Hence, for every screw in the fluidics system it was not noted what would happen if each one was missing due to the fact this was not a reasonable task or assumption to make due to the complexity and immense number of components in the system.

In concurrence with predicting a potential failure mode was determining the effects of the failure. For many of the potential failure modes there were numerous effects that could occur. In all cases the effects of the failure were assumed to be worst case scenario, so if necessary, a mitigation could be put in place. After the potential failure mode and effects of the failure were determined the severity was determined, based on this worst case scenario.

After the severity of the potential failure modes was determined the potential causes of the failure, process controls preventing the failure, occurrence rating, process 
controls detecting the failure, and detection rating could all be determined. The most challenging aspect to keep in mind when thinking about the process control detecting the failure was that this was the probability a defective unit would be detected before reaching the customer. In other words, the detection rating was based on the assumption that the potential failure mode would be caught on the manufacturing floor.

When determining the detection rating it is very reassuring to know that the complete fluidics module goes through a test procedure before it is assembled into a system. The procedure that is followed for the fluidics module test is the Manufacturing Test Procedure or MTP. When looking at the detection rating in the FMEA, the MTP for the fluidics module was an important consideration. In addition to the fluidics MTP, the entire medical instrument unit goes through a system level MTP and a burn in test period before it is ever shipped to a customer.

Another guideline that had to be set from the onset of the FMEA process was the threshold risk priority value where a mitigation was required. A risk priority value of 100 was chosen as the threshold point for a required mitigation. A value of 100 was suggested by the manufacturer's FMEA standard operating procedure and is a common used value for necessary mitigations to be put in place.

It is beneficial for the FMEA to be completed by individuals who are not part of the Research and Development team because there is a different understanding of the system. This allows issues not otherwise previously considered to be brought up for discussion. The Research and Development team was there supporting the FMEA effort, and made contributions in helping understand how the fluidics system functions and what 
could go wrong if specific items were assembled incorrectly or another error occurred during the assembly procedure.

The vitreoretinal system fluidics module FMEA spreadsheet was considered complete when each assembly step of all eleven fluidics sub-modules and the top level fluidics module had been thoroughly analyzed for potential failure modes.

\section{FMEA Data}

The complete Failure Mode and Effect Analysis spreadsheet for the fluidics submodule can be seen in Appendix IV. When completing the top level fluidics assembly FMEA there was a total of 164 line item entries for potential failure modes. Shown in Table 1 is a summary of the FMEA entries based on the fluidics sub-modules and the totals of the risk priority numbers that were greater than 100 and therefore required some type of mitigation.

\begin{tabular}{|l|l|l|}
\hline $\begin{array}{l}\text { Fluidics Sub- } \\
\text { Assembly: }\end{array}$ & $\begin{array}{l}\text { Total FMEA } \\
\text { Entries: }\end{array}$ & RPN > 100: \\
\hline Sub-Module L & 34 & 11 \\
\hline Sub-Module K & 42 & 12 \\
\hline Sub-Module J & 2 & 1 \\
\hline Sub-Module I & 9 & 3 \\
\hline Sub-Module H & 5 & 2 \\
\hline Sub-Module G & 18 & 4 \\
\hline Sub-Module F & 16 & 5 \\
\hline Sub-Module E & 27 & 6 \\
\hline Sub-Module D & 3 & 2 \\
\hline Sub-Module C & 5 & 0 \\
\hline Sub-Module B & 3 & 0 \\
\hline Sub-Module A & 0 & N/A \\
\hline TOTALS: & 164 & 46 \\
\hline
\end{tabular}

Table 1: Summary of the FMEA entries based on fluidics sub-modules 
It can be noted that the numbers of potential failure modes varied greatly based upon the complexity of the sub-module and the number of components and assembly steps that are involved.

\section{$\underline{\text { Results and Analysis }}$}

After the entire FMEA was completed for the top level fluidics assembly along with the eleven smaller sub-modules, there were forty-six possible failure mode entries that had to be addressed and some type of mitigation put in place. There was a variety of mitigations that could occur including drawing changes, training, field service guides, device history record checks, or a minor design modification. In addition to the forty-six mitigations the FMEA produced there were an additional twenty-nine suggestions from possible failure mode entries that had a risk priority number of less than one hundred.

Shown in Table 2 is a summary of the FMEA entries broken up into categories based upon the mitigation required. In addition to the required mitigations, the table also includes further suggestions that arose from the FMEA. These suggestions had a risk priority number of less than 100 and therefore were not required to be incorporated, but would provide clarification and be of a benefit to the assembly process. 


\begin{tabular}{|l|l|l|l|l|l|l|}
\hline $\begin{array}{c}\text { Fluidics Sub- } \\
\text { Assembly: }\end{array}$ & $\begin{array}{c}\text { Total } \\
\text { EMEA }\end{array}$ & $\begin{array}{c}\text { Total } \\
\text { RPN }> \\
100:\end{array}$ & $\begin{array}{c}\text { Drawing } \\
\text { Changes } \\
\text { Mitigation } \\
\text { for RPN }> \\
100:\end{array}$ & $\begin{array}{c}\text { Training } \\
\text { Mitigation } \\
\text { for RPN }> \\
100:\end{array}$ & $\begin{array}{c}\text { Other } \\
\text { Mitigation } \\
\text { (MTP, DHR } \\
\text { checks, } \\
\text { modification, } \\
\text { Field Service) } \\
\text { for RPN }>100:\end{array}$ & $\begin{array}{c}\text { Additional } \\
\text { Suggestions } \\
\text { for RPN } \\
100:\end{array}$ \\
\hline Sub-Module L & 34 & 11 & 5 & 3 & 3 & 5 \\
\hline Sub-Module K & 42 & 12 & 6 & 5 & 1 & 12 \\
\hline Sub-Module J & 2 & 1 & 0 & 1 & 0 & 0 \\
\hline Sub-Module I & 9 & 3 & 2 & 1 & 0 & 2 \\
\hline Sub-Module H & 5 & 2 & 0 & 2 & 0 & 0 \\
\hline Sub-Module G & 18 & 4 & 3 & 0 & 1 & 2 \\
\hline Sub-Module F & 16 & 5 & 1 & 1 & 3 & 3 \\
\hline Sub-Module E & 27 & 6 & 2 & 1 & 3 & 1 \\
\hline Sub-Module D & 3 & 2 & 1 & 1 & 0 & 2 \\
\hline Sub-Module C & 5 & 0 & N/A & N/A & N/A & 1 \\
\hline Sub-Module B & 3 & 0 & N/A & N/A & N/A & N/A \\
\hline Sub-Module A & 0 & N/A & N/A & N/A & N/A & 29 \\
\hline TOTALS: & 164 & 46 & 20 & 15 & 11 & 3 \\
\hline
\end{tabular}

Table 2: Summary table of required mitigations

There are many different complexities to the mitigations required, but all must be implemented before the vitreoretinal medical instrument can be put into production.

\section{$\underline{\text { Mitigations }}$}

There were a total of forty-six possible failure modes that required some type of mitigation to be put in place. There were a variety of mitigations that were implemented. After the mitigations were implemented a new risk priority number was calculated, and for all cases the mitigation lowered the original risk priority number to below 100 .

Furthermore, many of the additional suggestions that had a risk priority number of less than 100 were still mitigated for assembly improvements. For this table new risk 
priority numbers were not calculated since the original risk priority number was less than 100.

Now that all of the necessary mitigations and corrective actions are put in place from the completion of the FMEA, the fluidics module to the vitreoretinal surgery instrument can be assembled with confidence that there will be minimal failure modes and complaints.

\section{$\underline{\text { Discussion }}$}

After determining the mitigations for the possible failure modes it can be seen how important it is to analyze all of the potential failure modes so mitigations can be put in place. This in turn reduces the likelihood of customer complaints, maintenance and warranty costs, the possibility of safety failures, the possibility of extended life or reliability failures, and the likelihood of product liability claims.

The easiest solution to most of the potential failure modes is to add a required operator check after the assembly has been completed. However, in reality this is not the best solution because there is nothing to assure that it will get done. Therefore, the preference for the mitigation was to make the design error proof in every case where this was feasible. Even though all operators go through an extensive training and training is extremely important the preference is for a mitigation to make the failure mode less likely in addition to training. 


\section{Conclusions}

A Failure Modes and Effect Analysis, or FEMA, is an in depth tool to analyze potential failure modes. Completing the FMEA to the fluidics sub-module a vitreoretinal surgery system is a vital step to the development of new product in order to assure there is minimal risk.

One of the fascinating aspects about the FMEA for the medical instrument fluidics module is the fact that many facets of engineering were covered. In order to complete the FMEA successfully the mechanical, electrical, and biomedical areas engineering were all extensively involved.

The vitreoretinal surgery system can now be released to customers with assurance that there is minimal risk of potential harm to the patient or surgeon now that a complete FMEA has been performed on the fluidics module and the necessary mitigations have been put in place.

\section{Discussion for Future Work}

A vitreoretinal surgery system is clearly a very complex medical device. Completing a Failure Mode and Effects Analysis is extremely time-consuming, but it is of such great importance and cannot be overlooked. The fluidics portion of the medical instrument is by far the most complex and has the most potential for failure. However, Failure Mode and Effect Analyses have to be completed for all of the smaller and less complex sub-modules. In this way every assembly step of the entire system the potential failure modes have been analyzed in a way that could be managed. 
No matter how many times the assembly of the fluidics sub-module is analyzed there are always going to be the potential that improvements can be made. However, after completing the FMEA and addressing all of the necessary issues the manufacturer can feel with confidence that their product is not of risk to the surgeon or the patient.

Even after the medical instrument is released out into production there will always be improvements that can be made. Unfortunately, throughout the life of the vitreoretinal surgery system there will be many failure modes that could have never been predicted. It is for this reason that there is an extensive team at the manufacturer whose primary focus is to investigate failures and complaints. However, with the completion of the FMEA the number of failure modes and complaints is likely to be greatly reduced. 


\section{$\underline{\text { References }}$}

[1] "About Us: Irvine Technology Center." Alcon Laboratories, Inc. December 3, 2006. <http://www.alconlabs.com/us/aa/About_Irvine.jhtml >, 2006.

[2] "Accurus Field Service Training Manual." Alcon Laboratories, Inc. 2007.

[3] “Accurus Surgical System.” Alcon Laboratories, Inc. November 22, 2006. $<$ http://www.accurus.com/general/default.asp> 2006.

[4] "Age Related Macular Degeneration." National Eye Institute.

$<$ http://www.nei.nih.gov/health/maculardegen/armd facts.asp>. February 2008.

[5] “Alcon's Approach." Alcon Laboratories, Inc. May 22, 2007.

$<$ http://www.alcon.com/eye-health/approach.asp>, 2007.

[6] "Alcon At-a-Glance." Alcon Laboratories, Inc. May 22, 2007.

$<$ http://www.alcon.com/alcon-products/pharmacetical.asp>, 2007.

[7] "Alcon Business Divisions." Alcon Laboratories, Inc. May 22, 2007.

$<$ http://www.alcon.com/about-alcon/business-divisions.asp>, 2007.

[8] "Alcon Conditions \& Diseases of the Eye." Alcon Laboratories, Inc. May 22, 2007. $<$ http://www.alcon.com/eye-health/conditions-diseases.asp >, 2007.

[9] "Alcon Detached Retina." Alcon Laboratories, Inc. May 22, 2007.

$<$ http://www.alcon.com/eye-health/detached-retina.asp> $>, 2007$.

[10] "Alcon Irvine, California." Alcon Laboratories, Inc. May 22, 2007.

<http://www.alcon.com/alcon-locations/us-irvine-ca.asp> $>, 2007$.

[11] “Alcon Mission \& Core Competencies." Alcon Laboratories, Inc. May 22, 2007. $<$ http://www.alcon.com/about-alcon/mission-core-competencies.asp>, 2007.

[12] "Alcon's Mission: Eye Health." Alcon Laboratories, Inc. May 22, 2007. $<$ http://www.alconlabs.com/us/aa/About_Irvine.jhtml>, 2007.

[13] "Alcon People." Alcon Laboratories, Inc. May 22, 2007. $<$ http://www.alcon.com/about-alcon/people.asp>, 2007.

[14] "Alcon Pharmaceutical." Alcon Laboratories, Inc. May 22, 2007. $<$ http://www.alcon.com/alcon-products/pharmacetical.asp>, 2007.

[15] "Alcon Point of View." Alcon Laboratories, Inc. May 22, 2007. $<$ http://www.alcon.com/eye-health/point-view.asp>>, 2007.

[16] "Alcon Products." Alcon Laboratories, Inc. May 22, 2007. 
$<$ http://www.alcon.com/alcon-products/>, 2007.

[17] “Alcon Retina and Vitreous Surgery." Alcon Laboratories, Inc. November 22, 2006. <http://www.alconlabs.com/in/eo/surgery/VitretSurg.jhtml> 2006.

[18] "Alcon Surgical." Alcon Laboratories, Inc. May 22, 2007. $<$ http://www.alcon.com/eye-health/>, 2007.

[19] "Alcon The World of Eye Health." Alcon Laboratories, Inc. May 22, 2007. $<$ http://www.alcon.com/eye-health/>, 2007.

[20] Anderson, Nicholas et al. "Incidence of Intraocluar Pressure Spike and Other Adverse Events after Vitreoretinal Surgery." American Academy of Ophthalmology. 2006 January. Volume 113, Number 1.

[21] Bear, Mark F., Barry W. Connors, and Michael A. Paradiso. Neuroscience: Exploring the Brain Second Edition. Baltimore: Lippincott Williams and Wilkins, 2001.

[22] Charles, Steve and William O. Edward. "Vitreous." Vaughan \& Asbury's General Ophthalmology $-17^{\text {th }}$ Edition. 2008.

[23] Ciulla, Thomas et al. "Best Practices: Vitreoretinal Surgery." Review of Ophthalmology. 2000 August. 66-68.

[24] "CMV Retinitis Treatment." EyeMDLink.com. August 8, 2007. $\langle\underline{\text { http:}: / / w w w . e y e m d l i n k . c o m / E y e P r o c e d u r e . a s p ? E y e P r o c e d u r e I D=57>. ~} 2006$.

[25] "Coats of the Eye - Fibrous Layer," Alcon Laboratories, Inc. May 23, 2007. $<$ http://www.alconnet.com/groupTrng/upload/indexable/ATS/salestraining/Eye_Anatom y/CoatsoftheEye/FibrousLayer.htm>, 2007.

[26] "Coats of the Eye - Nervous Layer," Alcon Laboratories, Inc. May 23, 2007. $<$ http://www.alconnet.com/groupTrng/upload/indexable/ATS/salestraining/Eye_Anatom y/CoatsoftheEye/NervousLayer.htm>, 2007.

[27] "Coats of the Eye - Vascular Layer," Alcon Laboratories, Inc. May 23, 2007. $<$ http://www.alconnet.com/groupTrng/upload/indexable/ATS/salestraining/Eye_Anatom y/CoatsoftheEye/VascularLayer.htm>, 2007.

[28] Dieter, George E. Engineering Design: A Materials and Processing Approach $3^{\text {rd }}$ Edition. Boston: McGraw-Hill, 2000.

[29] Encyclopedia Britannica. "Focusing."

$<$ http://www.britannica.com/eb/art/print?id=100398\&articleTypeId=1>. 2006.

[30] "Epiretinal Membrane Peeling (Membranectomy)." EyeMDLink.com. August 8, 2007. $<$ http://www.eyemdlink.com/EyeProcedure.asp?EyeProcedureID $=50>.2006$. 
[31] “Eye." Microsoft( Encarta( ${ }^{\circledR}$ Online Encyclopedia 2008. January 5, 2008.

$<$ http://encarta.msn.com/encyclopedia_761564189/Eye.html > 2008.

[32] Gao, Shawn. "NGVS Fluidics Theory of Operation." Alcon Laboratories, Inc. 2007.

[33] Guyton, Arthur C., and John E. Hall. Textbook of Medical Physiology Eleventh Edition. Philadelphia: Elsevier Inc., 2006.

[34] Hartzell, Criss. "Looking Chloride Ion Channels Straight in the Eye: Bestrophins, Lipofuscinosis, and Retinal Degeneration." Physiology. 2005. Vol. 20. Pages 292-302.

[35] Kirchhof, Bernd, and David Wong. Vitreo-retinal Surgery. Berlin Heidelberg: Springer, 2005.

[36] "Laser for Diabetic Retinopathy." EyeMDLink.com. August 8, 2007. $<$ http://www.eyemdlink.com/EyeProcedure.asp?EyeProcedureID=55>. 2006.

[37] "Macular Degeneration." All About Vision.

$<$ http://www.allaboutvision.com/conditions/amd.htm> 2008.

[38] "Macular Hole." Vitreous-Retina-Macula Consultants of New York. April 3, 2008. <http://www.vrmny.com/pe/mh.html >. 2006.

[39] "Macular Hole Surgery." EyeMDLink.com. August 8, 2007.

$<$ http://www.eyemdlink.com/EyeProcedure.asp?EyeProcedureID=51>. 2006.

[40] "Macular Pucker." Vitreous-Retina-Macula Consultants of New York. April 3, 2008. <http://www.vrmny.com/pe/mp.html>. 2006.

[41] McDermott, Robin E., Raymond J. Mikulak, and Michael R. Beauregard. The Basics of FMEA. Portland: Productivity, 1996.

[42] "Manufacturing Test Procedure for Fluidics Module." MTP Fluidics Module 9072120-004. Alcon Laboratories, Inc. 2007.

[43] Natarajan, S. et al. "Recent Advances in Vitreoretinal Surgery." Journal of the Bombay Ophthalmologists' Association. 2005 April. Vol. 14 No. 1.

[44] "NIH National Eye Institute." U.S. National Institutes of Health: Research Today... Vision Tomorrow. August 15, 2007. <http://www.nei.nih.gov/>. 2007.

[45] Oshima, Yusuke, Masahito Ohji and Yasuo Tano. "Surgical Outcomes of 25-Gauge Transconjunctival Vitrectomy Combined with Cataract Surgery for Vitreoretinal Disease." Annals Academy of Medicine. 2006 March. Vol. 35 No. 3. 
[46] "Process and Equipment FMEA Guidance." Alcon Irvine Technology Center Standard Operating Procedure. ITCSOP 000787. 12 August 2005.

[47] "Proliferative Diabetic Retinopathy." Vitreous-Retina-Macula Consultants of New York. April 3, 2008. 〈http://www.vrmny.com/pe/p dr.html>. 2006.

[48] "Retinal Detachment Repair." EyeMDLink.com. August 8, 2007. $<$ http://www.eyemdlink.com/EyeProcedure.asp?EyeProcedureID=52>. 2006.

[49] "Retinal Tears and Retinal Detachment." Vitreous-Retina-Macula Consultants of New York. April 3, 2008. <http://www.vrmny.com/pe/rtrd.html>. 2006.

[50] Roe, Richard and H. Richard McDonald. "Complications of Vitreoretinal Surgery." Review of Ophthalmology. January 2008. 64-71.

[51] Silverthorn, Dee Unglaub. Human Physiology: An Integrated Approach Second Edition. New Jersey: Prentice-Hall, Inc., 2001.

[52] Stamatis, D. H. Failure Mode and Effect Analysis: FMEA from Theory to Execution Second Edition. Milwaukee: American Society for Quality, 2003.

[53] Tewari, Asheesh and Gaurav Shah. "Recent Advances in Vitrectomy Surgery." Retina Handbook. 2006 December. 3-6.

[54] "Visual System Introduction," Alcon Laboratories, Inc. May 23, 2007. $<$ http://www.alconnet.com/groupTrng/upload/indexable/ATS/salestraining/Eye Anatom y/VisualSystem/Introduction.htm> 2007.

[55] "Vitrectomy." EyeMDLink.com. August 8, 2007. $<$ http://www.eyemdlink.com/EyeProcedure.asp?EyeProcedureID=58>. 2006.

[56] "Vitrectomy." Vitreous-Retina-Macula Consultants of New York. April 3, 2008. $<$ http://www.vrmny.com/pe/vitrectomy.html >. 2006.

[57] "Vitreoretinal." EyeMDLink.com. August 8, 2007. $<$ http://www.eyemdlink.com/EyeProcedure.asp?EyeProcedureID=49>. 2006.

[58] "Vitreoretinal Surgery: Facedown Recovery for a Brighter Tomorrow." Vitrectomy Solutions. August 8, 2007. <http://vitrectomysolutions.com/tornretina.asp>.

[59] Wimpissinger, Barbara et al. "Miniaturized Instruments in Vitreoretinal Surgery: The Future?" Retina Today. Summer 2006. 32-33.

[60] "Wet Macular Degeneration." EyeMDLink.com. August 8, 2007.

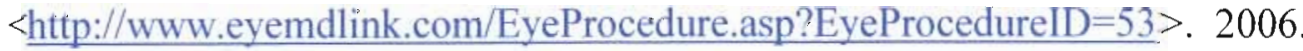




\section{APPENDIX I:}

\section{Eye Anatomy and Physiology}


The anatomy of the human eye and the neural pathways for vision are very complex. The actual process of seeing is not performed by the eye, but rather by the brain. The eye receives light rays reflected from objects around, focuses an image of those objects within the eye, creates sensory information from image light patterns, and transmits the sensory information to the brain. In other words, "the function of the eye is to translate the electromagnet vibrations of light into patterns of nerve impulses that are transmitted to the brain" [31]. This creates the sense of vision that allows humans to appreciate the beauty of the world, to read and gain knowledge, and to communicate though visual expression and visual arts.

In the process of vision light is reflected from objects in an individual's environment and translated into a mental image. There are numerous parts to the eye which all play an important role in vision. The retina, cornea, iris, lens, macula, and retinal blood vessels are only a few of these main parts and are shown in Figure 1. The process of vision is more easily understood when it is broken down into steps. During the first step of vision light enters the eye and is focused by the lens on the retina. The photoreceptors of the retina transduce light energy into an electrical signal during the second step. The final step of vision involves neural pathways and the processing of these

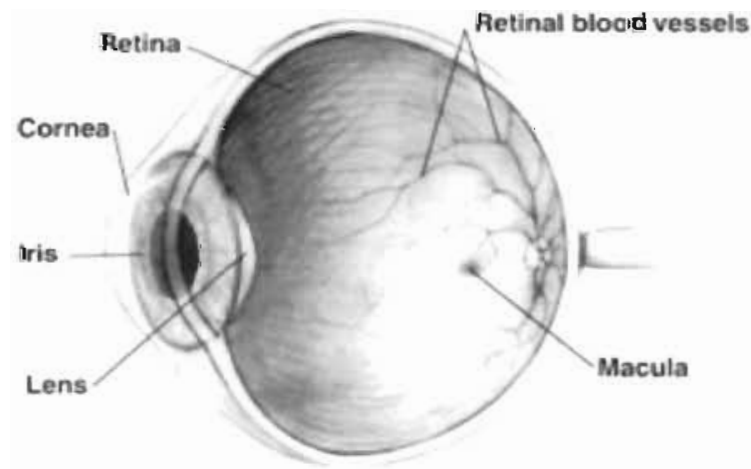

Figure 1: Anatomy of human eye from NIH National Eye Institute [44]

electrical signals. 
The human eye is approximately a spherical shape and has a diameter of roughly twenty four millimeters, or one inch [25]. The hollow sphere of the eye is divided into two sections which are separated by a lens. The gross anatomy of the human eye can be seen in Figure 2.

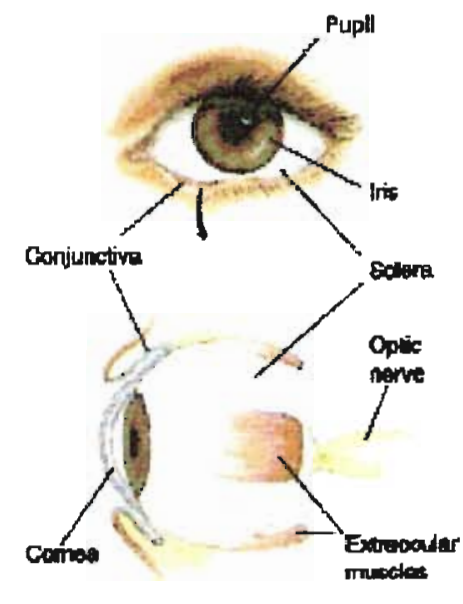

Figure 2: Gross anatomy of the human eye [21]

The eye is divided into two principal anatomical segments which are the anterior segment and the posterior segment. The anatomical segments of anterior and posterior are the terms that are used when referring to a required surgery. The locations of the anterior and posterior segments can be seen in Figure 3. The dividing line between the anterior and posterior segments is just behind the lens. The anterior segment extends forward from the posterior capsule of the lens.

It includes the lens, ciliary body, anterior chamber, anterior portion of the sclera, iris, and cornea. The posterior segment extends backwards from the portion of the vitreous in contact with the posterior capsule. The posterior segment is much larger than the anterior segment. It includes the vitreous, retina, choroids, sclera, optic disc, macula, and fovea. Aqueous humor fills both the anterior and posterior chambers of the eye.

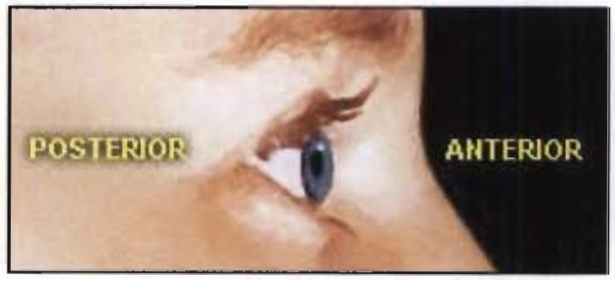

Figure 3: The anterior and posterior segments of the eye [54]

Moreover, intraocular fluid fills the eye to maintain sufficient pressure in the eyeball in order to keep it distended. The majority of the interior of the eye is taken up by the fluid filled cavities of the anterior and posterior segments. The compartment in 
front of the lens is filled with a low protein plasma-like fluid called the aqueous humor.

The aqueous humor is secreted by the ciliary epithelium supporting the lens. Vitreous humor, which is a clear and gelatinous matrix, makes up the large chamber behind the lens. The vitreous humor is made up of 98 percent water [22]. The eyeball stays distended due to

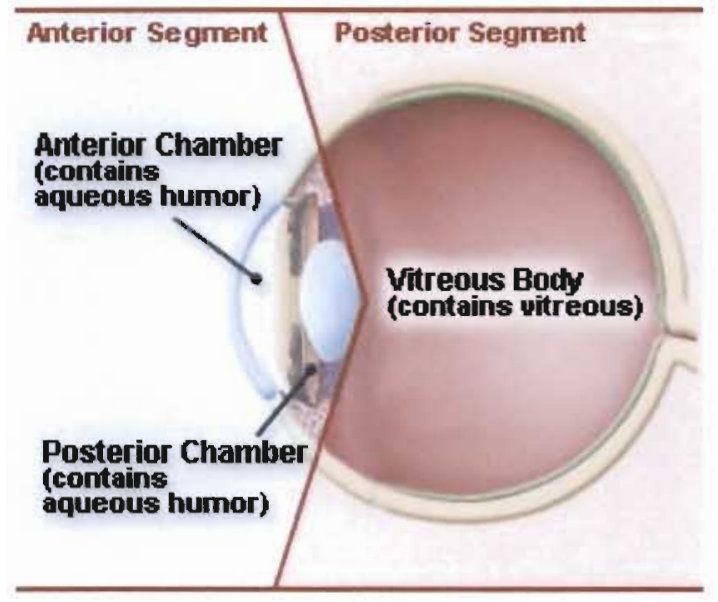

Figure 4: The fluids in each segment of the eye [54]

the pressure of the vitreous humor. These fluids play a vital role in maintaining ocular function. The fluids of each eye segment are shown in Figure 4.

The average normal intraocular pressure is about $15 \mathrm{mmHg}$, with a range from 12 to $20 \mathrm{mmHg}$ [33]. It is very important the eye remains in this range of intraocular pressure so the eye does not collapse or burst.

The pupil divides the anterior segment into two sections which are the anterior chamber and the posterior chamber. The ciliary processes produce aqueous humor which is a freely flowing fluid. The aqueous humor flows through the pupil into the anterior chamber. From the anterior chamber it drains out into a network of tiny blood vessels that surround the eye. The aqueous humor is continually being formed and reabsorbed. The total volume and pressure of the intraocular fluid is regulated by the balance between formation and reabsorption of aqueous humor.

The vitreous body or vitreous humor is a transparent, jelly-like substance that fills the cavity of the eyeball between the lens and the retina. The space between the lens and the retina is filled with vitreous and consists of a three-dimensional collagen fiber matrix 
and a hyaluronic acid gel [22]. The vitreous is permanently formed at birth and is made up of small fibers and water. The vitreous humor is a gelatinous mass held together by a fabrillar network composted primarily of elongated proteoglycan molecules [33]. Even though normal vitreous is essentially transparent it is capable of producing substantial force on the retina [22].

There is little flow of fluid in the vitreous humor, but water and dissolved substances can diffuse slowly in the vitreous humor. The vitreous provides the support and acts as a physical buffer for adjacent posterior segment structures such as the retina. A diagram of the formation and fluid flow in the eye can be seen in Figure 5.

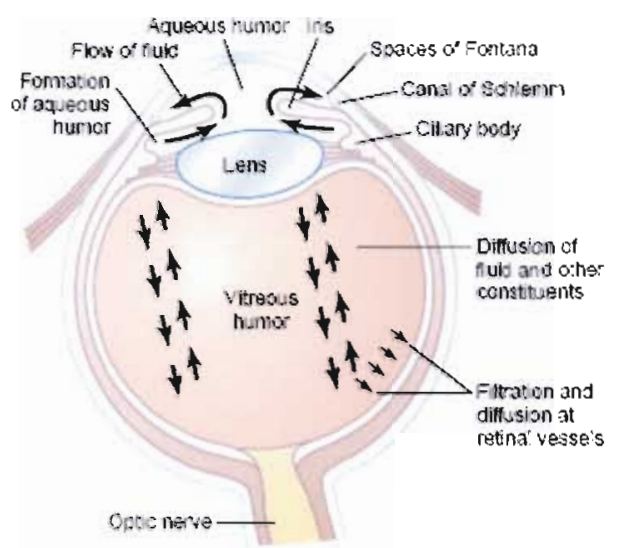

Figure 5: Formation and flow of fluid in the eye [33]

There are three main concentric layers or coats to the eye. These layers are the fibrous layer, vascular layer, and nervous layer. Each of the layers has different structures and functions. The external layer is formed by the sclera and cornea. The sclera acts as a protective coating and covers about five-sixths of the eye's surface. Next is the intermediate layer which is divided into two parts. The two parts are the anterior section containing the iris and ciliary body and the posterior section containing the choroid. The choroid is a vascular layer lining the posterior three-fifths of the eyeball. The final layer of tissues is the internal layer which is the retina. The retina is the sensory portion of the eye. 
The fibrous layer is the outermost layer of the eye which is extremely tough. It is composed of the sclera and the cornea. The sclera is the "white of the eye" and the cornea is the "window of the eye" [25]. The rigidity of the sclera gives the eye its shape. In addition, the sclera is opaque to exclude light. Light is admitted into the eye through the transparent and smooth cornea. Furthermore, the cornea has a curved surface which refracts light to help the lens focus images on the retina. The sclera and cornea are diagramed in

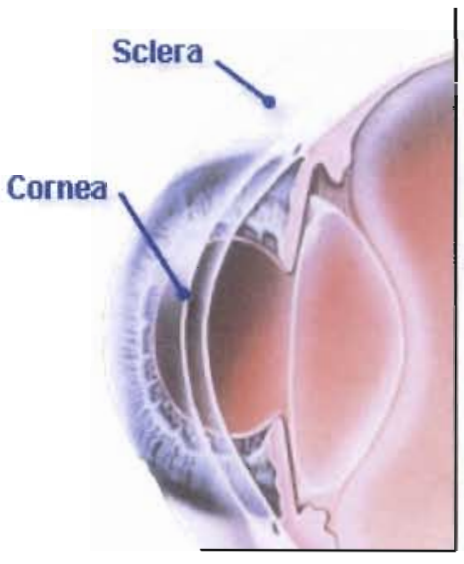

Figure 6: The sclera and cornea [25] Figure 6.

The sclera forms the tough wall of the eyeball. This fibrous layer is opaque so it prevents light from entering the eye except through the cornea. The spherical shape of the globe of the eye is protected and maintained by the rigidity and stiffness of the sclera. It is extremely important that the spherical shape of eye is maintained so patterns of light are properly focused on the retina and vision does not become impaired. The sclera is 0.5 to $1.0 \mathrm{~mm}$ thick and is composed primarily of connective tissue which has a high collagen content providing strength [25]. The region of outermost layers of the anterior portion of the sclera is known as episclera tissue and contains more blood vessels.

There are three pairs of muscles which are called the extraocular muscles and are inserted into the sclera. The extraocular muscles lie behind the conjunctiva and function to move the eyeball in the bony orbits of the skull. The locations of the sclera and conjunctiva are shown in Figure 7. The optic nerve is another major eye component 


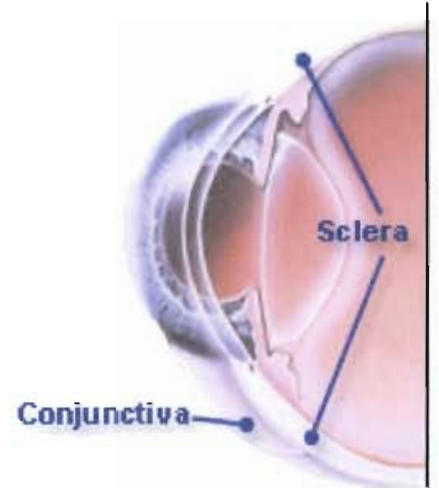

Figure 7: Locations of the sclera and conjunctiva [25] which has an important function. The optic nerve exits at the back of the eye and carries axons form the retina.

The thin, mucous membrane that lines the eyelids and sclera, but not the cornea is the conjunctiva. The primary function of the conjunctiva is to lubricate the outer layer of the eye. There are three main parts to the conjunctiva. These are the palpebral conjunctiva which coves the undersurface of the lids, the forniceal conjunctiva which forms a loose fold

in the area between the eyelid and eyeball, and the bulbar conjunctiva which coats the anterior portion of the sclera.

The choroid is a vascular membrane that separates the fibrous layer from the retina and makes up the posterior portion of the uveal tract. The central retinal artery that emerges from the back of the eye provides the blood to the choroid. In total, the choroid supplies all the eye layers with ninety percent of their blood supply. The fibrous layer and retina are supplied with nutrients from the blood vessel which are embedded in a meshwork of connective tissues. The blood vessels in the choroids are shown in Figure 8. The oxygen and metabolic needs of the eye are met by this blood supply. In addition, the blood supply provides the eye with the nourishment it needs to perform basic cellular functions and removes waste products from the eye. The pressure of fluids within the eye is closely related to the circulation of blood within the choroid.

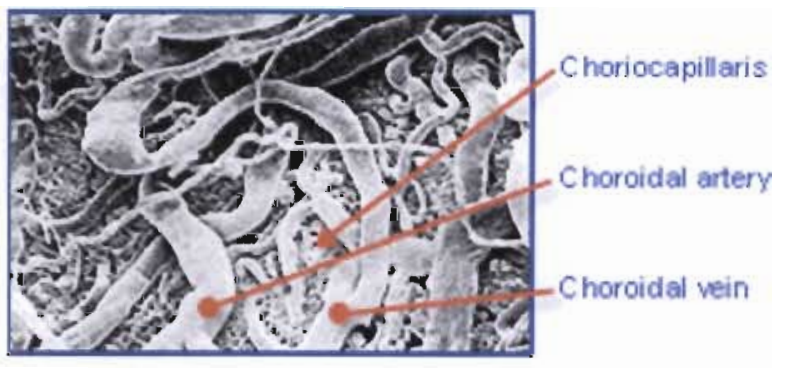

Figure 8: The blood vessels in the choroid [27] 
The choroid merges into the ciliary body towards the front of the eye. The structures of the ciliary body work together to produce the aqueous humor. The blood rich tissue of the ciliary body is made up of ciliary processes, ciliary muscles, and zonular fibers.

The shape of the lens during the process of focusing is controlled by the contractions of the ciliary muscle. Zonular fibers suspend the lens form the ciliary muscle. Both the parasympathetic and sympathetic nervous systems innervate the ciliary muscles. The ciliary muscles contract in response to parasympathetic stimulation and the muscles relax from sympathetic stimulation. Vision and the outflow of aqueous humor in the eye are both affected by changes in ciliary muscle tension. The folds on the surface of the ciliary body are called the ciliary process and are responsible for producing aqueous humor. Excess aqueous humor drains out of the eye through the canal of schlemm.

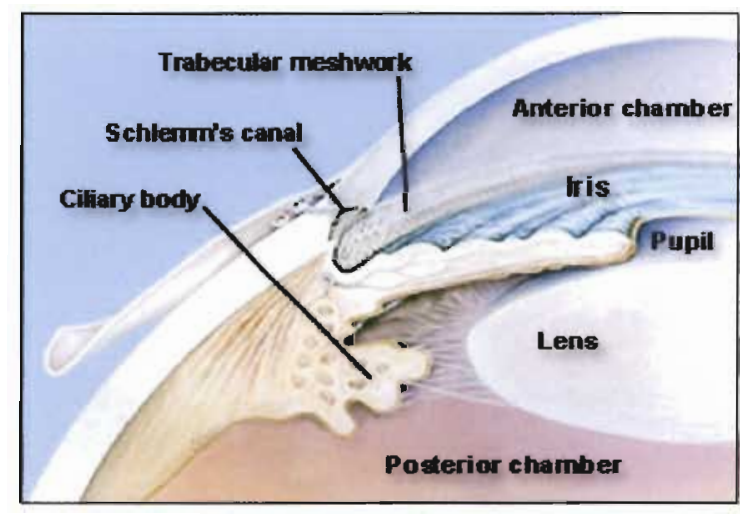

Figure 9: The structures of the uveal tract [27]

The vascular layer is the middle coat of the eye. It is also known as the uvea or uveal tract. There are three critical structures to the uveal tract. These include the iris, choroids, and ciliary body. Furthermore, the ciliary body is closely associated with the lens, trabecular meshwork, and anal of schlemm. A diagram of the structures of the uveal tract can be seen in Figure 9. 
The retina is the innermost layer, or nervous layer, of the eye and performs the function that gives the eye its purpose. The retina is a remarkable structure which is specialized to detect differences in the intensity of light falling on different aspects of it. The retina is a light sensitive surface at the back of the eye. Moreover, the retina contains photoreceptors that are specialized to convert light energy into neural activity. The remainder of the eye acts like a camera and forms images of the world on the retina. Just like a camera, the eye automatically adjusts to differences in illumination and automatically focuses itself on objects of interest.

Before any visual information reaches the rest of the brain there is image processing that is taking place in the retina. The retina absorbs light and transmits sensory information to the brain for processing [54]. The delicate and transparent neural tissue of the retina lines the posterior two-thirds of the eyeball and is $0.5 \mathrm{~mm}$ thick. The information transmitted to the brain travels by way of nerve fibers which are long cell extensions. The optic nerve is the bundle of nerve fibers that leaves the eye. There are blood vessels within the optic nerve that help nourish the retina. Shown in Figure 10 are the relative locations of the retina and optic nerve.

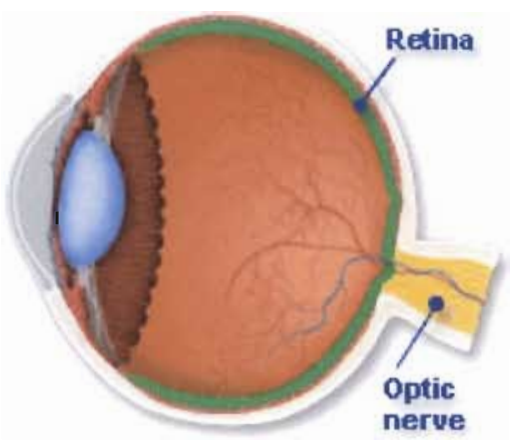

Figure 10: Diagram showing the location of the retina and the optic nerve [26]

The process in which the eye focuses images is in depth. There are three main structures that contribute to the eye's ability to focus images. These structures include the cornea, crystalline lens, and retina. Light rays first pass through the cornea which acts as a refracting and protective membrane. The crystalline lens acts as the focusing 
agent, changing shape so that images are focused on sensors in the retina. Optic nerves within the retina collect sensory information about the image and transmit it to the brain for interpretation as sight.

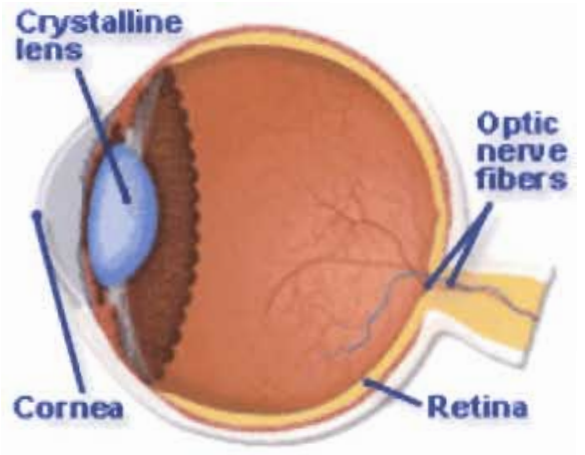

Figure 1 I: Relative positions of the anatomical structures of the eye's interior [54]

Figure 11 shows the relative positions of the anatomical structures of the eye's interior which are involved in focusing images. From the figure it can be seen that the cornea is anterior to both the lens and retina, the crystalline lens is posterior to the cornea and anterior to the retina, and the retina is posterior to both the cornea and lens. The optic nerve fibers are part of the retina to begin with, gather at the optic disc, and exit posterior to the eye.

The cornea is the transparent external surface of the eye which covers the pupil and iris and acts as a window for the eye. The cornea, shown in Figure 12, is a refracting and protective membrane in which light rays pass on their way to the retina. When looking at the eye from a cross sectional view the path light takes as it passes through the cornea toward the retina can be seen clearly. Due to the fixed shape of the retina it can refract light which contributes to the eye's ability to focus images. The cornea is a tough, rigid, and transparent structure in which the fibrous nature allows it to protect the eye. The role of the cornea is to serve as a barrier to the outside environment,

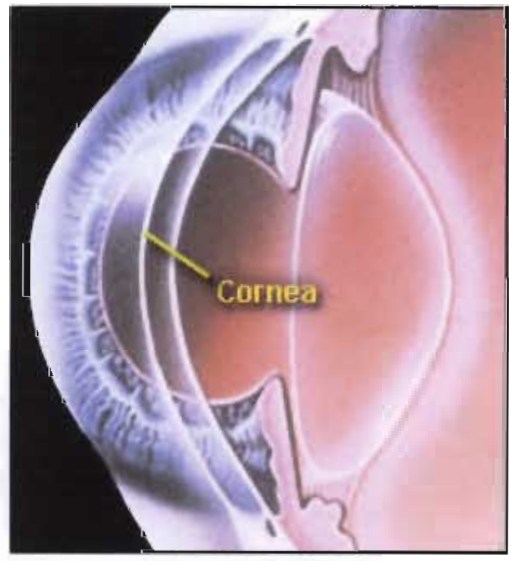

Figure 12: The cornea [54] 
preventing fluid loss and the invasion of pathogens or other harmful substances [54]. The surface of the cornea is made of many nerve endings with the role of alerting the brain if a foreign substance has entered the eye. In addition, the corneal nerves warn the brain when the eye is at risk of becoming too dry due to their sensitivity to a decrease in tears.

There are many sensory nerve endings contained in the cornea that mediate the pain response when the cornea is exposed to various stimuli. These stimuli include bright light, extremes of $\mathrm{pH}$, osmolarity or temperature, uncomfortable drugs or compounds, and touch [25]. As a response to this stimulation reflux tearing occurs. Shown in Figure 13 is the innervation of the corneal surface by nerve endings from the fifth cranial nerve [25].

There are no blood vessels contained in the cornea. Therefore, the cornea has to get its nourishment from the aqueous humor which is

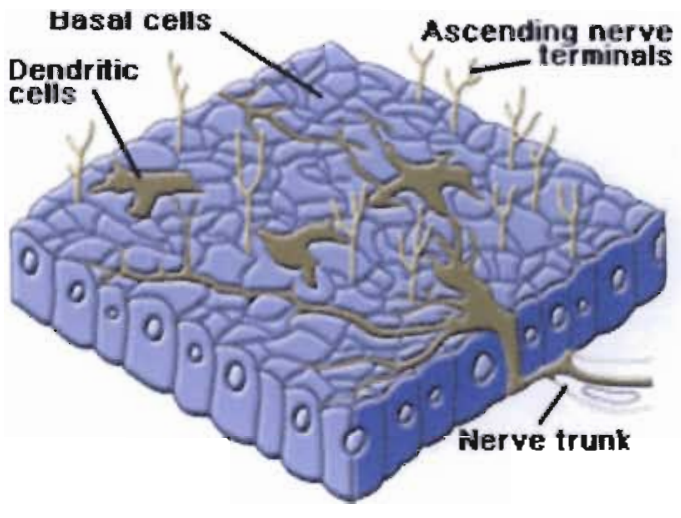

Figure 13: Innervation of the corneal surface by nerve endings from the fifth cranial nerve [25] the fluid behind the cornea along with the tear film that is on the outside which is continuously replenished by the blinking of the eyelids.

In order for images to be focused on the retina the cornea lets light enter the eye and refracts light into the lens. There are five distinct layers that make up the cornea. These include the corneal epithelium, Bowman's membrane, stroma, Descement's membrane, and corneal endothelium. These five layers together make the cornea around $520 \mu \mathrm{m}$ thick [25]. The cornea contains no blood vessels which mean that it is avascular and a transparent structure. The metabolic needs of the cornea are met by blood vessels 
supplying the limbus, fluids that make up the precorneal team film, components of the tear film aqueous, and oxygen from the external environment.

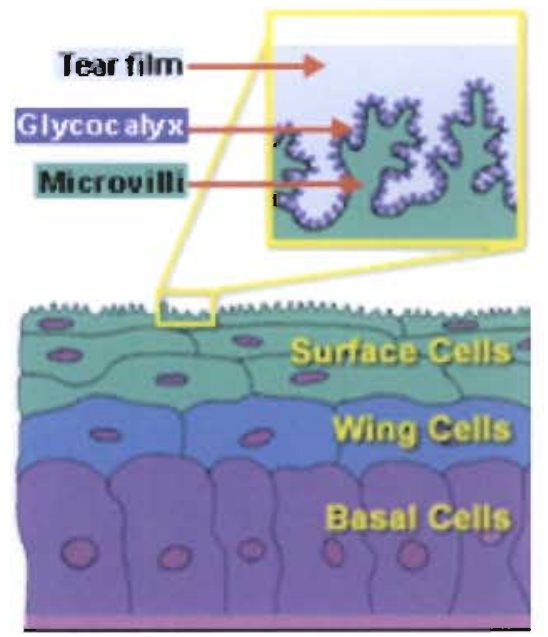

Figure 14: Diagram of corneal epithelial cells [25]
There are three types of cells that make up the corneal epithelium which is the outermost layer of the cornea. These three layers are the basal cells, wing cells, and surface cells which are shown in Figure 14. The basal cells make up a single layer that is tightly attached to the basement membrane, the wing cells are comprised of two or three layers, and finally there are two layers of elongated surface cells. The surface cells are joined by bridges that form junctions that regulate the passage of substances across the epithelial surface. The mucous secretions over the surface of the cornea are distributed by the microvilli which are tiny projections on the surface cells. There are long chain molecules on the surface of the microvilli which are called glycocalyx. The glycocalyx help hold mucin to the corneal surface.

The corneal epithelium undergoes constant regeneration like many other epithelial surfaces of the body. Superficial cells of the corneal epithelium are shed into the tear film and are replaced by newly formed cells every few days. The corneal epithelium tends not to scar in physiological conditions thanks to its excellent ability to regenerate.

In order for the cells of the corneal epithelium to remain healthy they must be kept moist. The precorneal team film, or PCTF, is a thin layer of lubricating substances that is responsible for keeping the corneal epithelium moist. A diagram of the precorneal tear film is shown in Figure 15. There are a number of important functions that the 
precorneal tear film performs. These include maintaining the health of the ocular surface, preserving clear vision, and

providing nutrition, waste removal, and antibacterial action. In addition, keeping cells moist, preventing the breakdown of epithelial cells, being the first line of defense against microbial infection, and ensuring comfort are all important functions of the precorneal tear film [25].

What is known as the colored portion of the eye is the

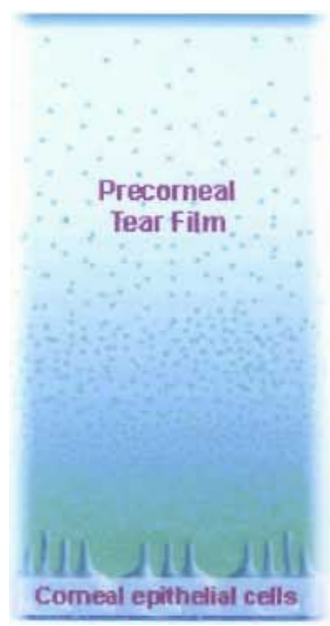

Figure 15: The precorneal tear film [25] iris and is located toward the front of the eye and represents the anterior portion of the uveal tract. The amount of light entering the eye is controlled by the muscles of the iris. There are pigments in the iris that give it its color. The iris contains smooth muscle fibers that adjust pupil size.

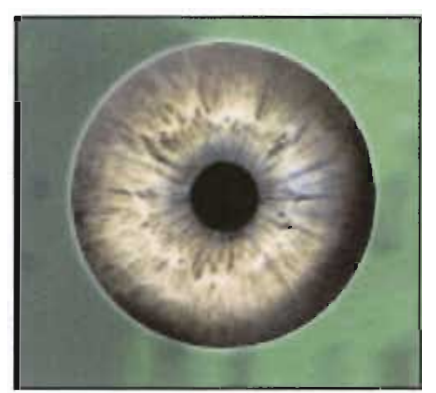

Figure 16: A diagram of the pupil [27]
The pupil is the black portion of the eye and is an opening that is created by the circular iris. The purpose of the pupil is to allow light into the eye and reach the retina. A diagram of the pupil can be seen in Figure 16. The pupil is black because of the lack of reflection of light from within the eye. There are light absorbing pigments in the retina which

make it appear dark. The iris surrounds the pupil and has pigmentation which gives the eye color. 
A pigmented epithelium, the anterior sphincter muscle, and the dilator muscle make up the iris. As smooth muscles the sphincter muscle contracts in response to parasympathetic stimulation, and the dilator contracts in response to sympathetic stimulation. When the amount of light falling on the retina changes, the pathways are stimulated or inhibited. In bright light the sphincter muscle contracts and the dilator muscle relaxes. This closes down the pupil and makes the opening smaller.

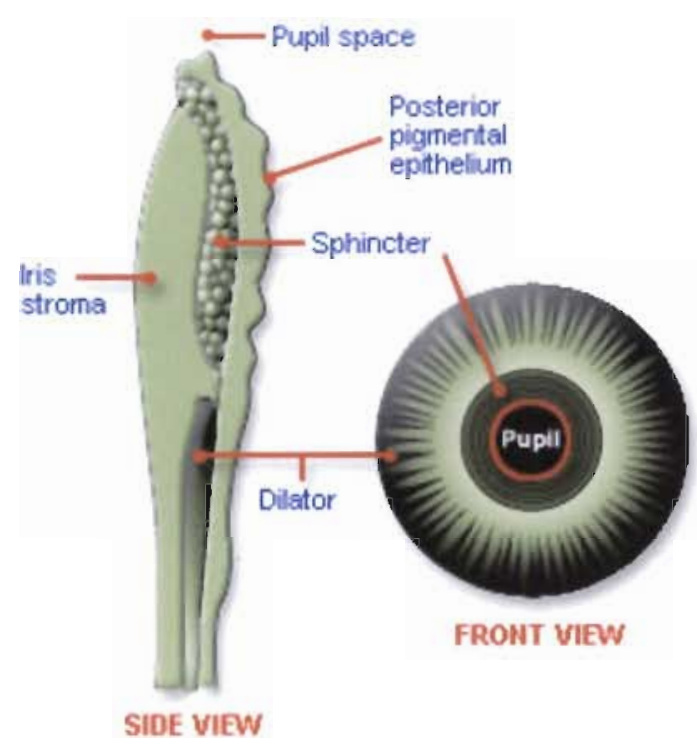

Figure 17: Detailed side and front view of the iris and pupil [27]
Furthermore, in dim light the sphincter muscle relaxes while the dilator muscle contracts. When this occurs the aperture is made larger and the pupil is opened up. The opening and closing by the smooth muscles controls the amount of light passing through the iris and falling on the retina to optimize illumination of the photoreceptors. A more detailed diagram of the iris and pupil can be seen in Figure 17.

Behind the iris located in the anterior portion of the eye is the crystalline lens which can be thought of as a focusing structure. When looking at a cross sectional view of the eye the location of the lens can clearly be identified. The crystalline lens is a transparent and flexible structure which contains no blood vessels. In order for the eye to see objects at a range of distances the crystalline lens changes shape to focus light rays on the retina. All of the nutrition that is required by the lens is obtained from the 
surrounding fluids, largely the aqueous. Consequently the external portion of the lens has a higher rate of metabolism than the internal portion.

The lens is suspended by zonular fibers which are attached to ciliary muscles. The ciliary muscles form a ring inside the eye and are attached to the sclera. The ciliary muscles have the capability of contracting and relaxing which cause the lens to change shape. It is these changes in shape of the lens that allow the eyes to adjust their focus to different viewing distances. Furthermore, the lens divides the interior of the eye into two different fluid compartments. The aqueous humor is a watery fluid that lies between the cornea and the lens and the vitreous humor which is more viscous jellylike fluid lies between the lens and the retina. The function of the vitreous humor is to retain the shape of the eye by keeping the globe of the eye spherical.

The majority of the crystalline lens is made up of lens fibers which are packed into tight layers. As individuals age the lens enlarges since new fibers are continually added. Lens fibers grow denser and less elastic with age which causes light to be focused less precisely and creates the possibility for vision to be impaired.

As light passes through the cornea and crystalline lens it is refracted before it reaches the retina. The shape of the lens plays an important role in brining objects into focus. In order so images are focused on the retina, the shape of the lens is changed by the ciliary muscle through accommodation. Accommodation is the definition for the adjustment
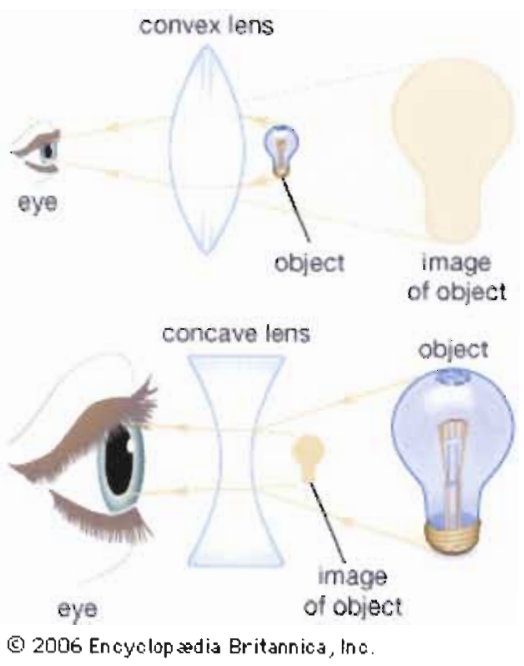

Figure 18: The shape of the lens allows objects to be brought into focus and seen clearly [29] 
of the lens from a flatter to a more spherical shape. The adjustment varies depending on the object's distance from the eye. Figure 18 shows how a convex lens produces magnified images of objects and concave lens produce small images of objects.

An ophthalmoscope allows an individual to peer into the eye through the pupil to the retina. The most obvious feature seen when looking at the eye through an ophthalmoscope is the blood vessels on the retina. The blood vessels of the retina originate from the optic disk which is the same location where the optic nerve fibers exit the retina. One interesting thing to note is that there are no photoreceptors located at the optic disk. Therefore, the sensation of light cannot occur at the optic disk. Furthermore, where large blood vessels exist there is also no sensation of light because the vessels cast shadows on the retina. Even though there are these areas where the sensation of light cannot arise an individual's perception of the visual world appears complete. The brain fills in the perception of the areas where there is no sensation of light allowing individuals to not see any holes in their field of vision.

The macula is the darker region at the center of the retina and is responsible for central vision. The quality of central vision is improved due to the absence of large blood vessels at this region of the retina. Another common anatomical reference point is the fovea and is located at the center of the retina. The fovea is the area where the retina is the thinnest and is especially capable of acute and detailed vision. The fovea occupies a total area of approximately one square millimeter [33].

There are three main layers in which make up the retina. These include a pigmented layer, neural layer, and a nerve fiber layer. The layers of the retina are shown in Figure 19. 
The outer layer of the retina is the pigmented layer and contains pigmented epithelial cells that absorb light and store vitamin $\mathrm{A}$. The role of the pigmented layers is to completely absorb any light rays that bypass the cones and rods so that stray light rays do not reflect back into the photoreceptors.

The front most layer of the retina is the nerve

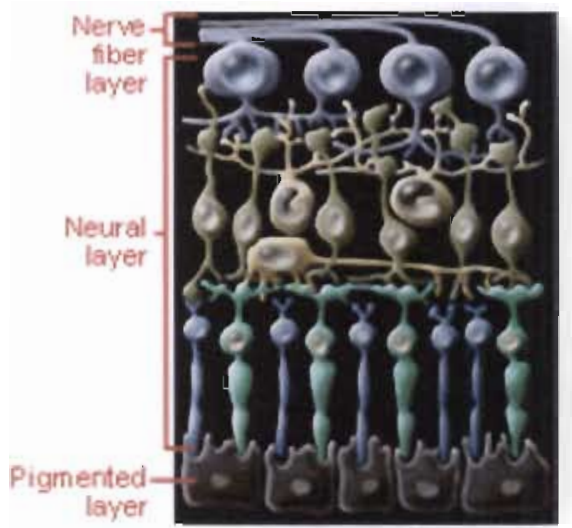

Figure 19: The three main layers of the retina [54]

fiber layer. It consists of nerve fibers from cells that originate in the neural layers along with blood vessels.

The middle layer of the retina is the neural layer which is made up photoreceptors and nerve cells that transmit visual information. The role of a photoreceptor is to convert

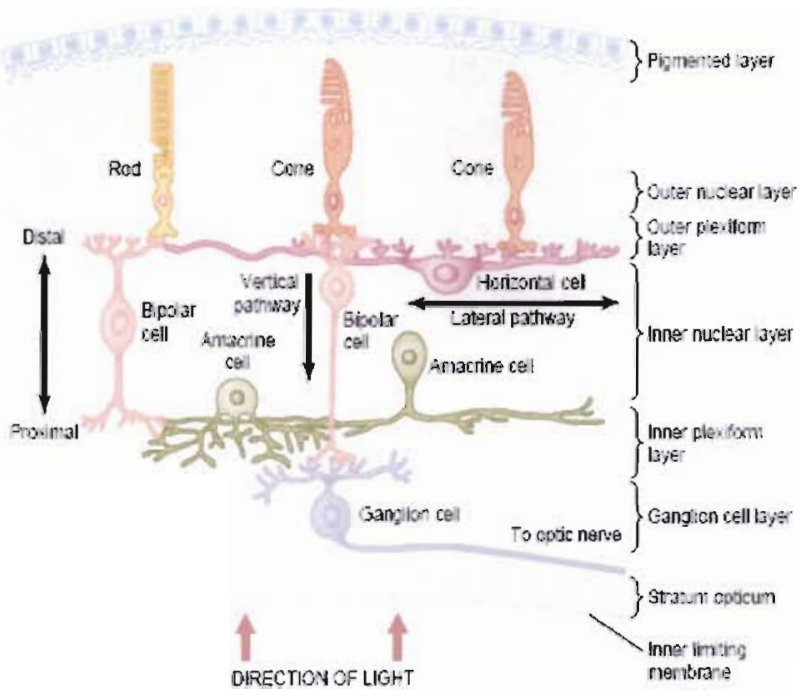

Figure 20: The layers of the retina showing the cells and photoreceptors [33] light into electrical impulses. The

neural layer is made up of

photoreceptor cells. These

photoreceptor cells generate sensory

information about the striking light

patterns and the nerve cells which send

the light pattern information to the

brain. Light enters the retina from the

inside of the retina after it passes

through the lens system and vitreous 
humor of the eye. A more detailed diagram of the layers of the retina including all the cells and photoreceptors is shown in Figure 20.

The visual pathway from the foveal portion of the retina is shown on the right side of Figure 21. The three neurons in the direct pathway are the cones, bipolar cells, and ganglion cells. Furthermore, horizontal cells transmit inhibitory signals laterally in the outer plexiform layer, and amacrine cells transmit signals laterally in the inner plexiform layer [31].

Moreover, neural connections for the peripheral retina are shown on the left side of Figure 21. In this area there are both rods and cones. The output from the bipolar cells pass only to amacrine cells which relay the information to the ganglion cells. There are four neurons in the direct visual pathway for pure rod vision which are rods, bipolar cells, amacrine cells, and ganglion cells. The lateral

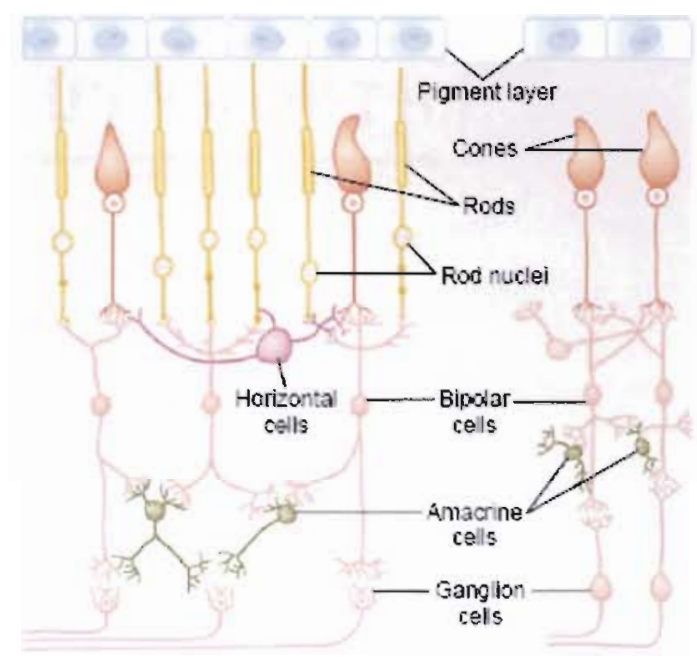

Figure 21: The neural organization of the retina. The peripheral area is to the left and the foveal area is to the right [33]

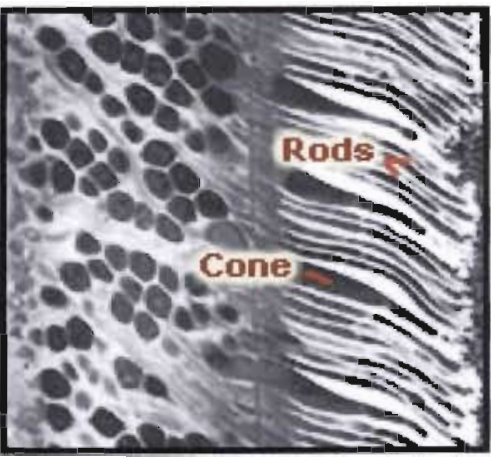

Figure 22: A microscopic view of rods and cones [26] connectivity in the retina is provided by the amacrine cells and horizontal cells [33].

The two types of photoreceptors are cones and rods

which are located on the outer neural layer of the retina. Cones detect bright light and color vision and rods are sensitive to dim light, responsible for black and white vision, vision in the dark, and process peripheral vision. Cones are 
denser in the center of the eye's visual axis in where the sharpest vision is received, and rods are peripherally located to the center visual axis to help detect images surrounding the center of gaze. A microscopic view of rods and cones can be seen in Figure 22.

Signals are transmitted through successive layers of neurons in the retinal when rods and cones are excited. Then the signals are transmitted into optic nerve fibers and the cerebral cortex. The outer segment, the inner segment, and the nucleus are the three major functional segments of either a rod or cone. The essential components of a rod or cone are shown in Figure 23. The light-sensitive photochemical is found in the outer segment of a rod or cone. The light-sensitive chemical in rods is called rhodopsin and in cones is called color pigments in cones [33]. Both rhodopsin and color pigments are conjugated proteins.

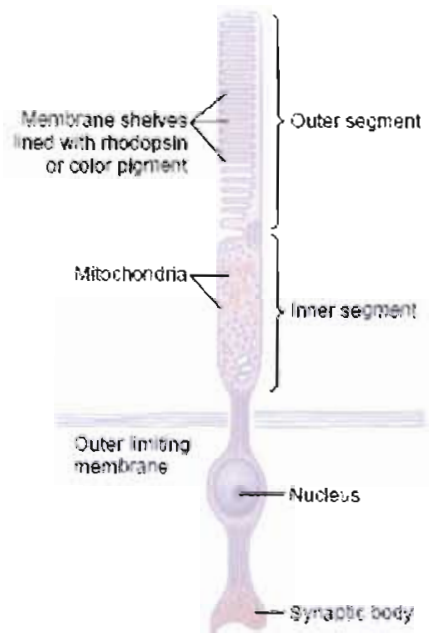

Figure 23: Schematic drawing of the functional parts of the rods and cones [33]

Nerve fibers are long cell extensions in which sensory information that the retina transmits travel. The optic nerve is where these nerve

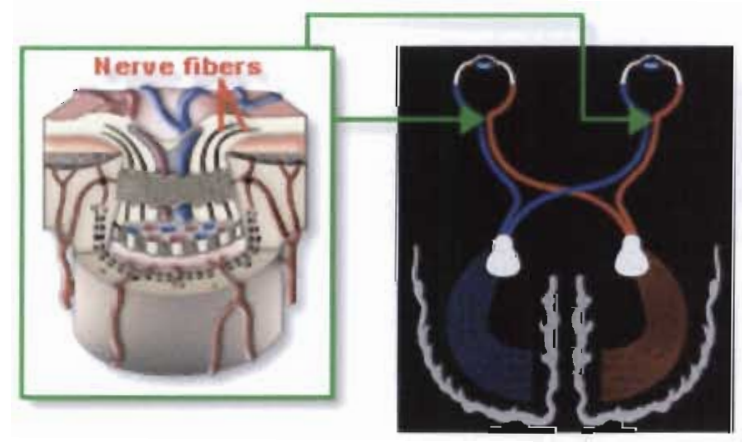

Figure 24: The optic nerve [26] fibers leave the eye bundled together after gathering together at the optic disc. The eye is connected to the brain through the optic nerve. The optic nerve carries electrical impulses which are to be translated into images. A diagram of the optic nerve is shown in Figure 24. 
The optic disc is the head of the optic nerve as it enters the eye from the brain. The optic disc is located slightly to the nasal side of the globe and is known as the blind spot due to the fact that it contains no photoreceptors. Therefore, any light that is focused on the optic disc cannot be converted into sensory impulses nor sent to the brain for interpretation. Shown in Figure

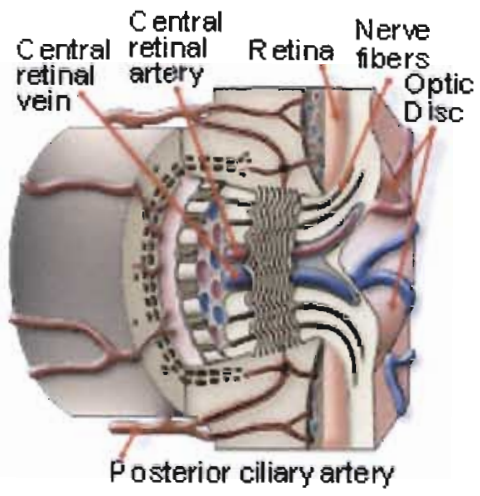

Figure 25: The optic disc [26]

25 is the optic nerve head.

The optic disc has many functions and features. It is the collection point of the nerve fiber layer as it exits the eye, is where the nerve fiber layer becomes the optic nerve, is where the central retinal artery enters the retina, and is where the central retinal

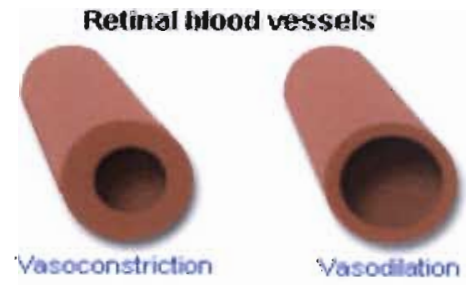

Figure 26: Vasoconstriction and vasodilation [26]

vein exits the retina. In addition, the optic disc is called the blind spot, is about 1.5 millimeters in diameter, and is round or slightly ovoid [26].

Based on the need, the retina is capable of regulating its own blood supply through vasodilation and vasoconstriction which are diagramed in Figure 26.

In addition to receiving blood from a vasculature in the choroids, the retina receives some of its blood supply from the central retinal vein and the central retinal artery. The central retinal vein and the central retinal artery are wrapped in the nerve fibers of the optic nerve. Figure 27 shows the sources for the blood supply for the

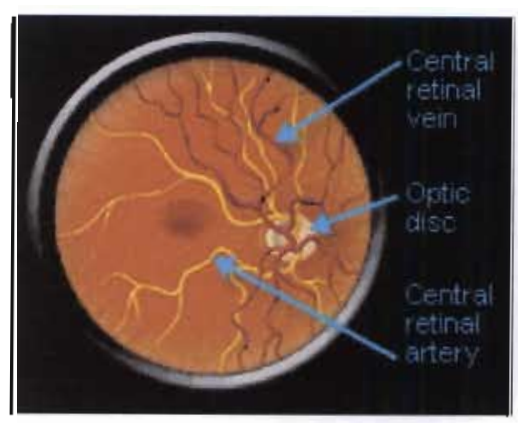

Figure 27: The sources of blood supply for the retina [26] 
retina.

The anterior part of the eye is supplied with blood by the lacrimal artery. The posterior ciliary artery supplies the choroids with blood. Furthermore, these blood vessels give the inner layers of the retina the needed nutrients they need. The outer portion of the retina is nourished mainly by vessels from the choroids.

After reviewing the anatomy and physiology of the human eye and how the process of vision works the complication and detail of vitreoretinal surgery can be more easily appreciated. 


\section{APPENDIX II:}

\section{Vitreoretinal Surgery}


The concept of vitreoretinal surgery is an amazing achievement of modern medicine to help treat patients that might otherwise be blind. Vitreoretinal surgery has enhanced and restored vision in numerous individuals due to the forefront of new instrumentation and surgical techniques. The recent advancements in vitreoretinal surgery have come a long way, but there are still complications and challenges that arise with today's vitreoretinal surgery procedures and techniques.

Vitreoretinal surgeries are extraordinarily complex surgeries that require an in depth understanding of the human eye to comprehend and appreciate the technology that is involved in the research and development of a new vitreoretinal surgical system. A diagram of a surgeon's view of the human eye during vitreoretinal surgery can be seen in Figure 28. The intricacy and fragility of the

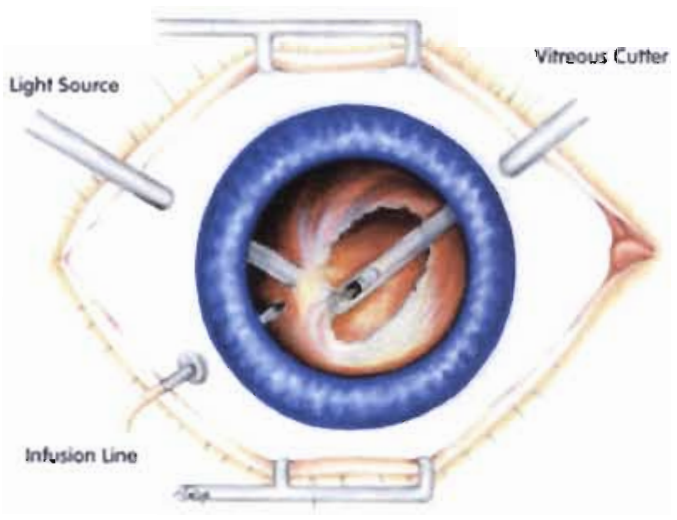

Figure 28: A surgeon's view during vitreoretinal surgery [56] human eye show the complexity of vitreoretinal surgeries for surgeons. It is important to have a basic understanding of the human retina and vitreous in order to understand why a vitreoretinal surgery may be required and beneficial to the patient. Many times retinal and vitreous problems can cause a severe loss of vision or even blindness.

The retina has two parts which are the peripheral retina and macula. The peripheral retina is the large area of the retina which surrounds the macula and makes up ninety-five percent of the retina. The peripheral retina gives humans vision to the sides which is also known as peripheral vision. However, the peripheral retina is not able to 
see detail clearly. Humans cannot use peripheral vision to read, drive, or even recognize a face. Furthermore, the vitreous is the material that fills the central cavity of the eye. The vitreous is attached to the retina. The vitreous is most strongly attached to the optic nerve, the macula, and the large retinal blood vessels which are all in the back portion of the eye.

Vitreoretinal surgeries can be performed to treat many conditions of the retina. There are three main reasons that an individual may require vitreous surgery. These include shock or trauma, disease, and anterior segment handling of the vitreous [2]. Shock or trauma can cause blood to be emptied into the vitreous, causing the vitreous to become cloudy and impairing vision. Disease often causes vitreous retinal bonding problems which may require surgery. Disease can cause a variety of cell changes to occur within the vitreous and cause a detachment of the retina. The final main reason for vitreous surgery is due to anterior segment handing of the vitreous. If vitreous enters the anterior chamber of the eye following cataract surgery, it must be surgically dealt with or it can cause significant problems such as retinal detachment.

The common goal of all vitreoretinal procedures is to restore, enhance, and preserve vision. There are several various surgical and laser procedures that may be required as a result from a vitreoretinal disease. The vitreoretinal surgery procedure begins with the removal of vitreous body, blood, or inflammatory material from the vitreous cavity. The most difficult challenge in surgically dealing with the vitreous is that it is easy to get entangled with vitreous and pulling the collagen fibers which in turn can cause a retinal detachment. After the substance is removed from the vitreous cavity the disease whether it be a retinal detachment, macular hole, proliferative diabetic 
retinopathy, intraocular foreign body, or another vitreoretinal disease, can be treated in situ. There is a wide variety of fine intraocular instruments, fluids, and gases that can be used depending on the procedure. Some of the most common vitreoretinal procedures include pneumatic retinopexy, scleral buckling, and vitrectomy.

During a pneumatic retinopexy procedure a gas bubble is placed inside the vitreous cavity. A pneumatic retinopexy has been a popular and straight forward way to repair rhegmatogenous retinal detachments since the 1980s [49]. Pneumatic retinopexy is especially a popular method for repair if there is a single break located in the superior portion of the retina or top part of the eye. In order to help seal the retinal hole permanently the hole is treated with laser or cryotherapy. The purpose of the gas bubble over the hole of the retina is to prevent fluid from entering the hole while the retina heals. As expected there are advantages and disadvantages to a pneumatic retinopexy procedure. The main advantage to the pneumatic retinopexy approach is that it can be performed in a doctor's office and there is no hospitalization required. However, precise head positioning is required after a pneumatic retinopexy procedure for approximately seven to ten days.

Furthermore, scleral buckling is a common vitreoretinal surgery procedure. The scleral buckling procedure has been used for more than forty years and was the only procedure available until approximately twenty-five years ago [49]. Scleral buckling is a procedure in which a soft silicone band is placed around the eye to indent the outside of the eye towards the detached retina. Therefore, the vitreous grip on the retinal hole is relieved. The location and number of retinal breaks determines the type and shape of the buckle. The scleral buckle is kept in place with sutures to the sclera. The buckle is 
positioned so that it pushes on the retinal break to effectively close the break. After the scleral buckling procedure many times at the site of the retinal detachment the vitreoretinal surgeon removes the fluid under the retina and seals the hole with laser of

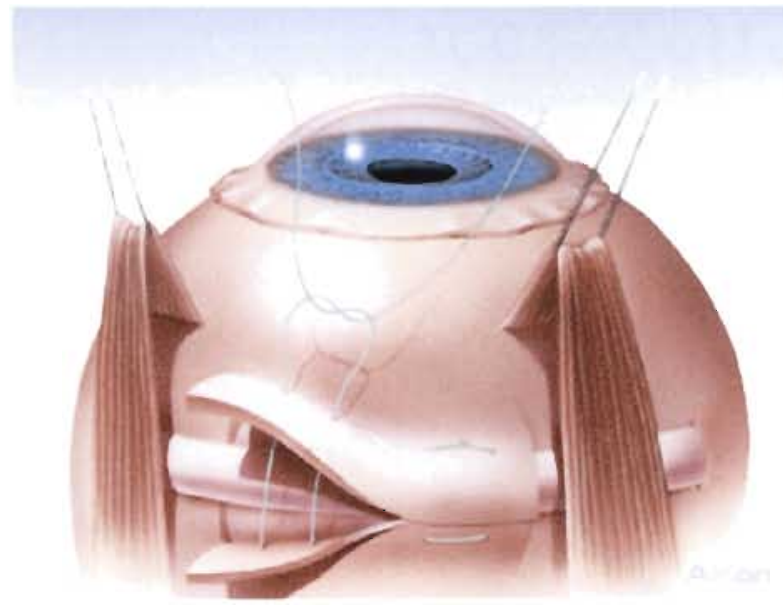

Figure 29: A diagram of the scleral buckling procedure [2] cryotherapy. However, the fluid under the retina can also spontaneously resolve over one to two days. A diagram of the scleral buckling procedure can be seen in Figure 29. The main advantages to the scleral buckling procedure are the patient is in and out of the hospital on the same day and there are no post operative positioning requirements.

Furthermore, a vitrectomy is a commonly performed vitreoretinal procedure. The vitrectomy procedure was first used approximately twenty-five years ago and has been continuously refined and improved.

Furthermore, over the last five to ten years the vitrectomy procedure has become the initial surgery of choice for repair of many vitreoretinal diseases [49]. A vitrectomy is a procedure in which the vitreous humor is removed from the eye. Figure 30 shows the vitreoretinal surgery instruments entering the eye through the pars plana in order to

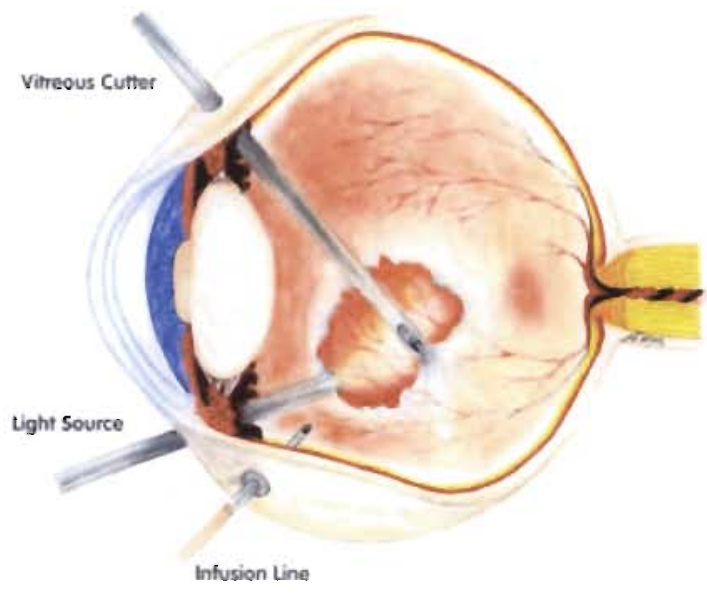

Figure 30: Vitreoretinal surgery instruments entering the eye through the pars plana in order to remove the vitreous [56] 
remove the vitreous. There are many reasons as to why a vitrectomy should be performed. Some of these include diabetic vitreous hemorrhage, retinal detachment, epiretinal membrane, macular hole, proliferative vitreoretinopathy, endophthalmitis, intraocular foreign body removal, or retrieval of lens nucleus following complicated cataract surgery.

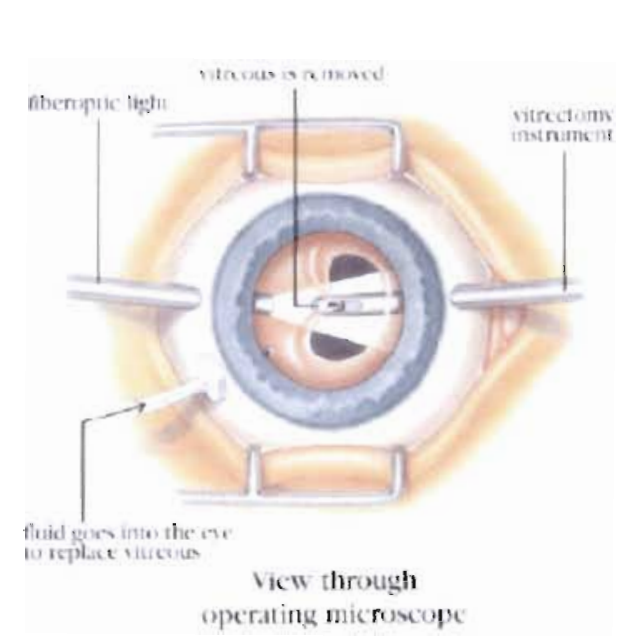

Figure 31: The three incisions or sclerotomies used for posterior segment surgery [2]
Vitrectomy surgery is typically performed using 20 gauge instruments with three separate incisions or sclerotomies. The separate sclerotomies are usually used for an infusion port, illumination, and vitreous suction and cutting. A diagram of the three incisions or sclerotomies used for posterior segment surgery can be seen in Figure 31.

For a vitrectomy intraocular scissors

were developed for membrane cutting. Certain diseases of the eye cause membrane bands to grow. When dealing with these bands surgically the objective is to cut these bands with as little traction on the retina as possible. The small instruments utilize a guillotine cutting device that safely removes the vitreous while replacing it with saline. The cutting device has a guillotine movement along with an oscillating microscope cutter that is capable of removing the vitreous in a slow and controlled manner. A diagram of membrane cutting with intraocular scissors can be seen in Figure 32. It is extremely important that the cutting action is slow and controlled so that there is no gripping on the 
retina during the removal of the vitreous humor. After the vitreous is safely removed typically laser photocoagulation or cryotherapy is used to repair the retina.

Vitrectomy procedures have a very high success rate. The recovery rate depends on a many factors with the preoperative condition being the greatest. The patient is

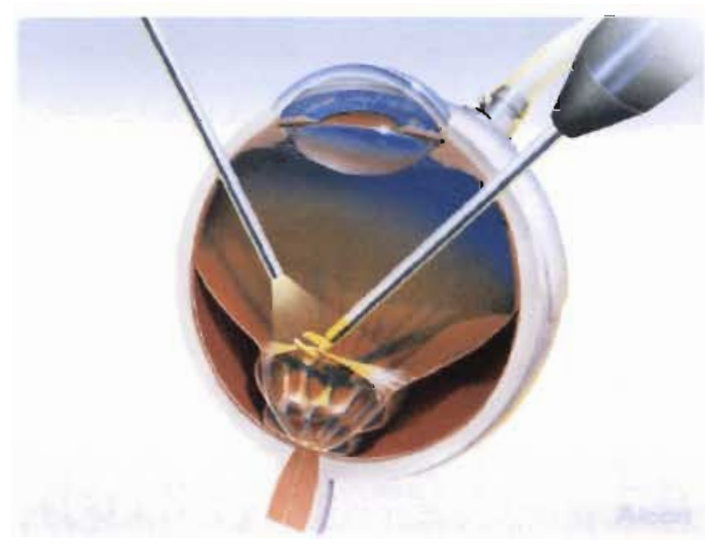

Figure 32: Membrane cutting with intraocular scissors [2] usually out of the hospital the same day the vitrectomy was performed. Complications are relatively unusual; however, there are potential complications as with any surgical procedure. Some of these potential complications include bleeding, infection, progression of cataract, and retinal detachment [55]. Depending on the vitreoretinal procedure a specific head position may be required to keep the retina attached.

Furthermore, a procedure called Fluid/Gas exchange may be attempted in some cases of severe vitreoretinal disease. In this type of procedure the eye is filled with gas to push the retina into its original position. A laser or some other similar instrument will be used to reattach the retina once the retina is pushed back into position. Once the retina is in its original position, the air will be removed and a vitreous substitute will be used to replace the intraocular volume.

There is a wide variety of reasons for which some form of vitreoretinal surgery can be required. Some of the most common examples for vitreoretinal surgery include:

- Retinal detachment or retinal breaks

- Macular degeneration 
- Diabetic retinopathy

- Macular hole

- Epiretinal membrane

- CMV retinitis

- Severe eye trauma

- Complications of cataract surgery

One of the main reasons that vitreoretinal surgery is required is for retinal detachments. The separation of the retina from the back wall of the eye is called retinal detachment and can occur for various reasons. A retinal detachment can occur over time as the liquid in the vitreous cavity collects under the retina and lifts it up off the back wall of the eye. If a tear in the retina occurs, the liquid in the vitreous cavity can pass through the tear and get under the retina. When there is a tear or a hole in the retina fluid is allowed to get underneath the retina, and the vitreous no longer adheres to the retina and creates a cavity between the vitreous and the retina. When this occurs, the attachment is weakened and the retina becomes detached and is not capable of composing a clear picture from the incoming rays and vision becomes blurred and dim. A retinal detachment can also occur if the bond of the vitreous is not solid against the inner lining of the retina. When the retina is detached it is separated from the back wall of the eye and then no longer receives the necessary blood supply and nutrition required to function. Wherever the retina becomes detached vision is lost. A diagram of the cross section of an eye with a retinal detachment can be seen in Figure 33. 
Retinal detachment has a

large impact on the global

population. In the United States

detached retinas affect about one

person in ten thousand and are most

prevalent in middle aged, short-

sighted individuals [58].

Furthermore, detached retinas often

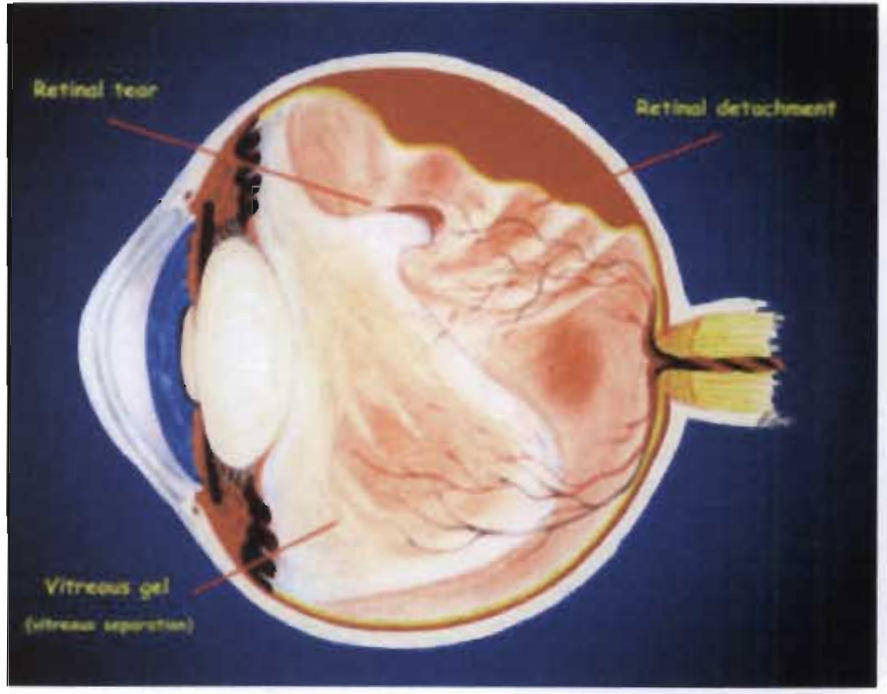

Figure 33: A cross section of the eye with a retinal detachment [47]

occur in individuals who are myopic

as they age. A pattern of occurrence for detached retinas also appears following cataract

surgery. With the increasing age of the population, increasing incidence of cataracts, and taking into account the world prevalence of short-sightedness, there is a great potential for an immense increase in the cases of detached retinas in the future.

There are many common symptoms of retinal detachments. The most common is a loss of peripheral vision. In addition, a shadow may spread across the vision of one eye and be accompanied by bright flashes of light or showers of dark spots called floaters.

Patients with a family history of retinal detachment, patients who are nearsighted, patients who have previously had cataract surgery, and patients with trauma to the eye are at a higher risk for a retinal detachment [58]. It is uncommon for a detached retina to be painful, but prompt treatment is necessary to minimize the damage to the eye.

The causes of a retinal detachment can be divided into three main categories.

These are rhegmatogenous, exudative, and traction retinal detachments [49]. A rhegmatogenous retinal detachment is the most common type of retinal detachment. It is 
due to a retinal break or tear that allowed the liquid vitreous to pass though the break and detach the retina. In addition, an exudative retinal detachment is due to leakage from under the retina creating fluid that detaches the retina. Exudative detachments can be caused by tumor and inflammatory disorders. Lastly, traction retinal detachments are due to pulling on the retina which is usually from fibro-vascular tissue within the vitreous cavity. One common cause of traction retinal detachments is proliferative diabetic retinopathy which will be discussed later

The treatment for a detached retina may only involve a minor surgical procedure if it is addressed early enough. However, many times an operation to repair the hole in the retina will be needed. The location of the retinal detachment and the extent of the repair before surgery largely determine the length of recovery. Patients with a retinal detachments that involve the macula, or central retina, are going to have a slower recovery than patients who only have a peripheral retinal detachment. Antibiotic and anti-inflammatory eye drop medications are required after a retinal detachment surgery. In ninety percent of cases the damage can be repaired with a single operation thanks to the medical advancements of vitreoretinal surgery devices [48].

There are three main surgical procedures which are used to treat a retinal detachment which depend on the circumstances of the retinal detachment. The retinal detachment procedures include pneumatic retinopexy, scleral buckling, and vitrectomy.

Moreover, age-related macular degeneration is another reason for vitreoretinal surgery. Macular degeneration is one of the leading causes of vision loss and blindness in America today, and is an increasing problem with the aging population [37]. Almost every person knows an individual, whether it is a parent, grandparent, or friend, that is 
affected with macular degeneration. Drastic life style changes occur when an individual loses the ability to see fine details, read, or recognize faces.

Macular degeneration occurs when the macula experiences thinning, atrophy, or bleeding. The macula is the light sensitive tissue at the back of the eye located in the center of the retina and allows an individual to see fine detail. Central vision can be lost or blindness can arise when an individual suffers from macular degeneration. Macular degeneration is referred to as age-related macular degeneration, or AMD, when it occurs beyond the fifth decade of an individual's life and has no specific diagnosis or known cause. Today age-related macular degeneration is the leading cause of blindness in technologically developed countries [34]. A picture of a field of view for an individual with age-related macular degeneration can be seen in Figure 34.
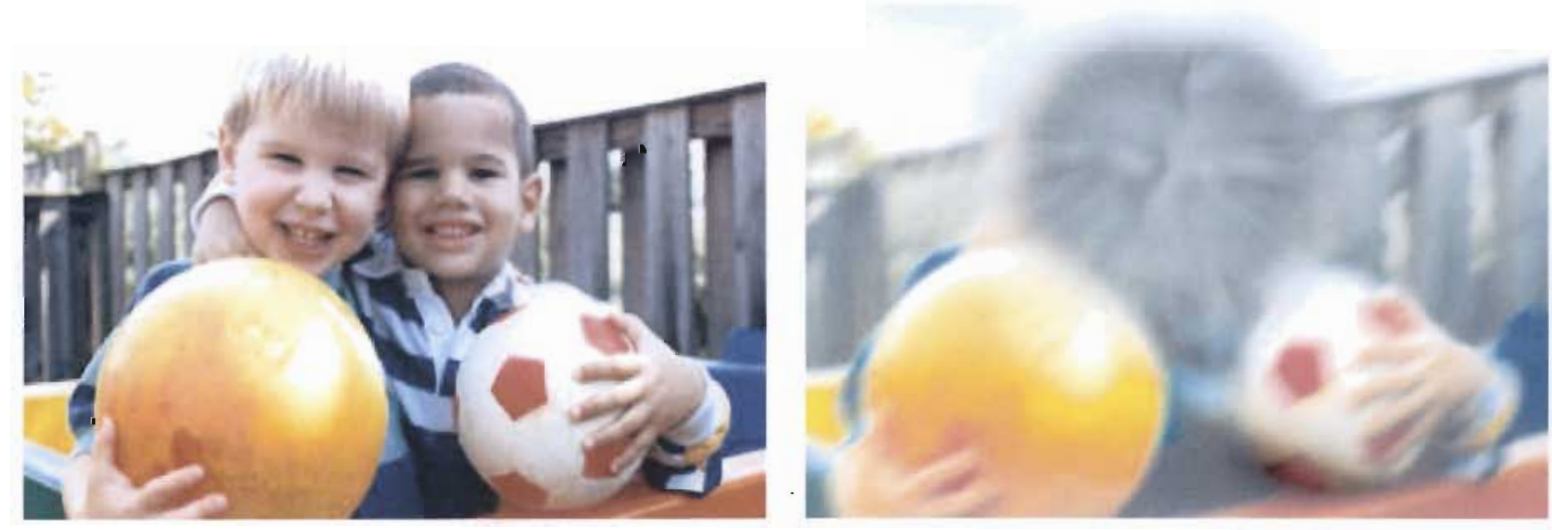

Figure 34: Normal vision and the same scene as viewed by a person with age-related macular degeneration [4]

At the beginning of macular degeneration the macula is filled with yellow deposits [37]. These abnormal accumulations of a fatty yellow pigment are called lipofuscin, and they are located in retinal pigment epithelial cells. Lipofuscin can damage the photoreceptors that are essential for high resolution central vision and disturb the pigmented cell layer under the macula. The lipofuscin accumulates between the 
retinal pigment epithelium and the underlying choroid. When the lipofuscin deposits become large and numerous, the pigmented cell layer under the macula is disturbed greatly increasing the risk for macular degeneration. However, the cause of macular degeneration is not well understood. Both genetic and environmental factors contribute to age-related macular degeneration making it challenging to study.

It is known that there are two forms of age related macular degeneration which are dry and wet AMD. Dry AMD is the more mild form of the disorder and accounts for about ninety percent of AMD patients [60]. There is not presently any Food and Drug Administration approved treatment for the dry form of AMD. Wet AMD is a more debilitating form of AMD, but fortunately only occurs in approximately ten percent of AMD patients [60]. There are two forms of laser treatment used to treat wet AMD. The first is traditional argon or diode laser therapy. In addition, photodynamic therapy is a more recent treatment for wet AMD.

In addition, individuals with diabetic retinopathy may require vitreoretinal surgery. A major cause of vision loss in diabetic patients is due to diabetic retinopathy. Diabetic retinopathy is the leading cause of acquired blindness amongst American under the age of 65 [36]. Patients who have proliferative diabetic retinopathy may have blood in the vitreous from retinal neovascularization.

The first step in the development of diabetic retinopathy is retinal ischemia. Retinal ischemia occurs when retinal blood vessels become damaged and close off due to the cumulative effects of diabetes and the peripheral portions of the retinal circulation begin to close down causing the retinal to become oxygen deficient [47]. When the retinal is ischemic chemical messages or growth factors are released. These growth 
factors lead to the growth of new blood

vessels or neovascularization in the eye. A

drawing of proliferative diabetic retinopathy

can be seen in Figure 35. The abnormal

vessels grow on the surface of the retina, at

the optic nerve, or in the front of the eye on

the iris [47].

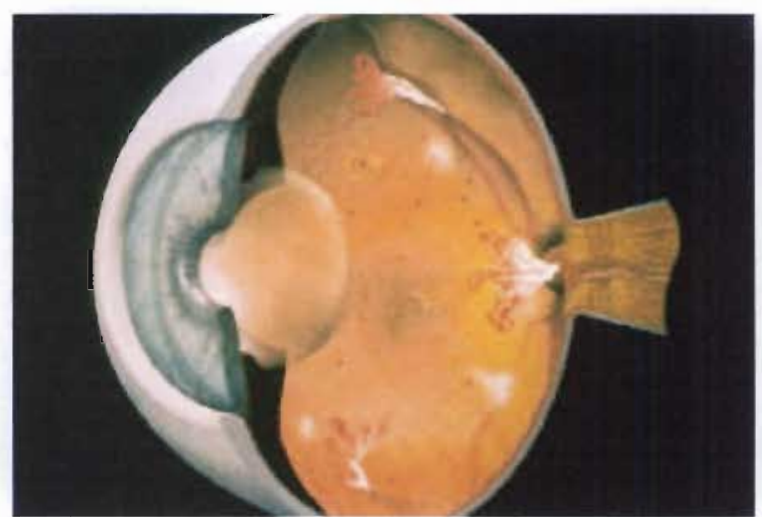

Figure 35 A drawing of proliferative diabetic retinopathy [47]

Neovascularization is not good because new vessels cannot replace the flow of necessary nutrients for the eye. The new vessels cause problems because they are fragile

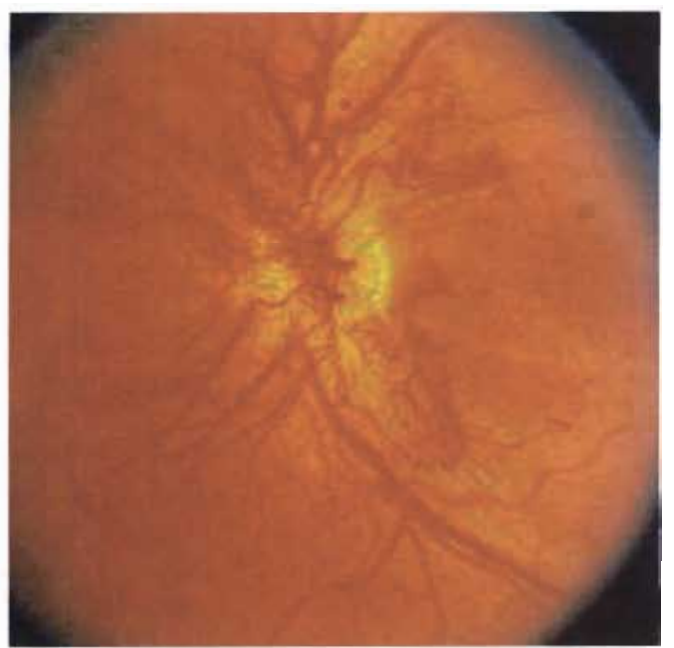

Figure 36: A color retinal photograph centered on the optic nerve demonstrating proliferative diabetic retinopathy and neovascularization [47] and prone to bleeding. Some of these problems

include vitreous hemorrhage, retinal

detachment, and uncontrolled glaucoma or high

pressure in the eye. A retinal photograph

centered on the optic nerve demonstrating

proliferative diabetic retinopathy and

neovascularization can be seen in Figure 36.

If a blood vessel breaks blood can spill

out into the clear vitreous gel which fills the

hollow central part of the eye. This bleeding is referred to as a vitreous hemorrhage. A vitreous hemorrhage can result in a sudden and rapid decrease of vision. Sometimes a vitreous hemorrhage will be absorbed by the body. Nevertheless, if the blood does not clear on its own a vitrectomy surgery is required to remove the vitreous that is filled with blood. Scar tissue can exert traction on adjacent structures as new tissues grow within the 
eye. Furthermore, pulling can distort the retina and lead to retinal detachment. In addition, if a vessel grows in the front of the eye on the colored iris the fluid outflow channels can be clogged greatly increasing the pressure in the eye.

The first step to the treatment of diabetic retinopathy is scatter laser photocoagulation or pan-retinal laser photocoagulation, which is a laser treatment of the ischemic peripheral retinal. This procedure should be performed as soon as the condition is diagnosed. The laser photocoagulation procedure causes a regression of the neovascular tissues and greatly reduces the risk of severe vision loss [36]. However, there are some patients with diabetic retinopathy that cannot have the laser treatment due to vitreous hemorrhage in which the blood gets in the way of the laser beam. If a vitreous hemorrhage is the case then a vitrectomy surgery is performed followed by laser photocoagulation.

Another reason for vitreoretinal surgery is for the treatment of a macular hole. A macular hole is a spontaneous development that predominately arises in aging women [39]. The macula is the central portion of the retina and provides high quality and detailed vision for tasks such as reading, watching television, or driving. A macular hole is when a break occurs in the macula. The vitreous shrinks as an individual ages causing the vitreous to move causing pulling on the retina and the possibility for a hole to form. After the formation of the hole vitreous can seep though the hole causing a centralized separation of the retina. When the central portion of the retina separates a dark spot and distortion to the central vision occurs [38].

Vision usually worsens as a macular hole develops and progresses. It is challenging to diagnosis a macular hole in the early stages of development. However, 
there are many symptoms once a macular hole has been diagnosed. These symptoms include decreased central vision for distance and reading activities, distortion in central vision, or a small defect in the central vision where small letters may disappear [38]. The surgical procedure to repair a macular hole begins with a vitrectomy procedure. The vitrectomy involves the microscopic surgical removal of the vitreous within the center of the eye. After a vitrectomy is performed, the membrane on the macula is usually removed which is called membrane stripping. In order to keep the macular hole closed while the retina heals a gas bubble is then placed in the vitreous cavity. For complete healing additional pressure must be exerted on the portion of the retina with the macular hole.

The challenge that arises with the gas bubble is the patient must remain in a face down position for one to two weeks following the surgery in order to keep the gas bubble over the macular hole. For the bubble to have the maximal effect the bubble must apply continuous upward pressure against the retinal surface. For the best outcome of the macular hole procedure the patient must remain in the face down position for two to three weeks after surgery. A diagram of a macular hole with the patient in the face up position on the left and in the face down position on the right can be seen in Figure 37. Typically six to eight weeks after surgery the gas bubble will be reabsorbed by the body. After the bubble is reabsorbed the vitreous cavity will be filled by liquid that is produced by cells in the front of the eye. 

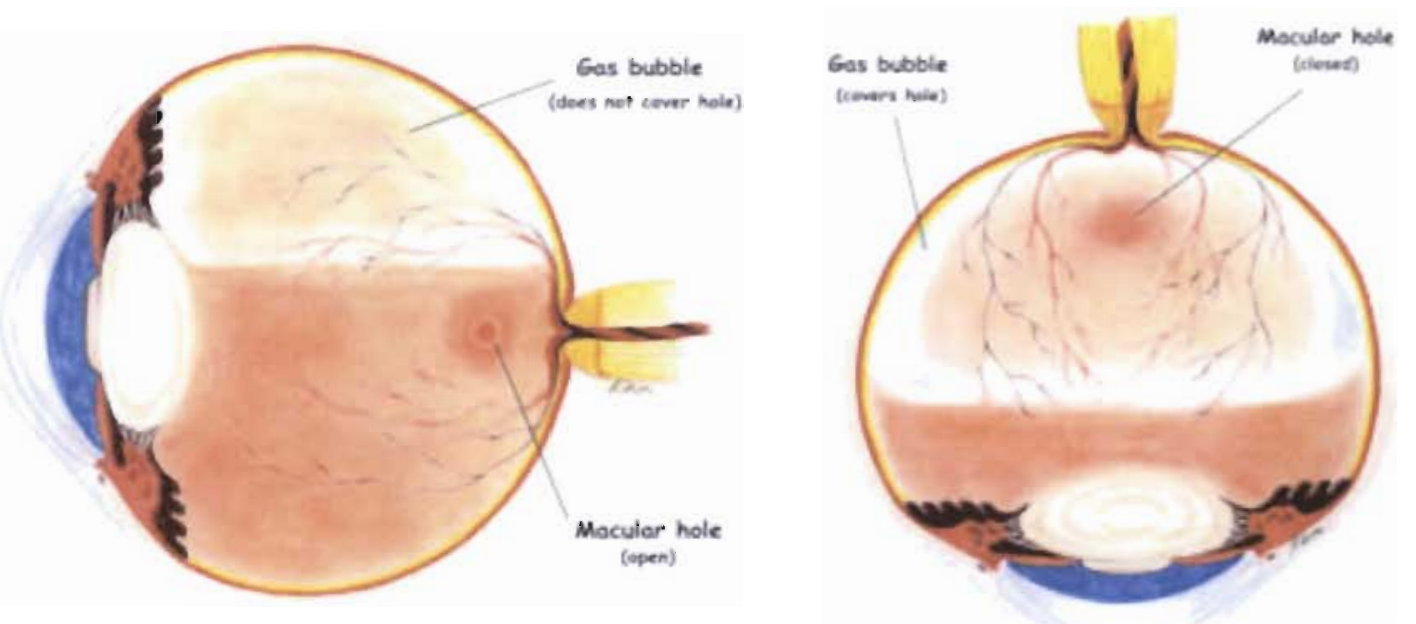

Figure 37: A diagram of a macular hole with the patient in the face up position on the left and in the face down position on the right [38]

However, an alternate approach to the gas bubble placement is to inject silicone oil within the vitreous cavity when the surgery is completed. The main advantage to the silicone oil injection method is a face down recovery is not required for the patient. However, a follow-up surgery is required to remove the silicone oil usually within a few months following the first surgery.

Like most procedures, there are risks and possible complications associated with surgery to treat a macular hole. Some of these complications include bleeding, infection, retinal detachment, glaucoma, and progression of cataract [39]. In patients that have not already had cataract surgery a cataract will develop in almost individuals within six months to a two years after the macular hole procedure. It is then required the cataract be surgically removed and the placement of an intraocular lens [38]. However, as long as the patients remains in the face down postoperative position macular hole surgery is an easy, painless procedure with a successful track record of improving or virtually restoring vision $[58]$. 
Furthermore, an epiretinal membrane can require vitreoretinal surgery. Epiretinal membrane is also known as macular pucker, surface wrinkling retinopathy, cellophane retinopathy, and internal limiting membrane disease. Epiretinal membrane is when a thin layer of scar tissue or membrane grows across the surface of the macula. This thin layer of scar tissue results in mechanical wrinkling and distortion of the retina. In most patients with an epiretinal membrane the growth taking place is extremely slow and eventually the scar tissue stops proliferating or extending [40]. Then over time contraction or pulling on the cells can cause a wrinkled or rippled appearance to this scar tissue. Therefore, the retina becomes wrinkled itself as the scar progresses since the scar cells are attached to the retina.

When epiretinal membrane peeling occurs central vision is interfered with due to distortion of the central retina. Patients with epiretinal membrane peeling often see objects as wavy or crooked in addition to the reduction of the central vision. Furthermore, patients may have distortion in lines or letters while reading, a decrease in central vision for distance and reading activities, and blurring or distortion of images while watching television [40].

In many cases there is no treatment required for an epiretinal membrane especially if the distortion is minimal. However, if it is determined that surgery is required to repair an epiretinal membrane a vitrectomy is first performed to microscopically remove the vitreous gel from the center of the eye. The membrane is then peeled away from the retinal using extremely fine forceps and high magnification. Sutures are required to close the incisions, but generally will not have to be removed at a later date. An epiretinal membrane procedure is one of the most delicate operations 
performed on the eye [30]. With an epiretinal membrane procedure full visual recovery many not occur for at least three to four months following the procedure.

Like other vitreoretinal procedures there are potential complications and side effects associated with an epiretinal membrane surgery. A small percentage of patients develop retinal tears or detachments during the procedure or during the immediate post operative period [40]. Furthermore, the development of a cataract may occur more rapidly in a patient having a vitrectomy for an epiretinal membrane, along with infection or bleeding.

Moreover, Cytomegalovirus infection of the retina, or CMV retinitis, can require vitreoretinal surgery. CMV retinitis is an ocular condition that affects AIDS and immune compromised patients. Patients with CMV retinitis patients usually experience small floaters, foggy or blurred vision, or loss of central or peripheral vision [24]. Patients that are diagnosed with CMV retinitis are usually treated with an antiviral medication. However, about twenty-five percent of patients who develop CMV retinitis will also develop a retinal detachment [24]. There are several factors associated with CMV retinitis that have a factor in determining if a retinal detachment is likely to occur. These factors include the size of the infected retina, an anterior location of the retinitis, a delay in medical management, myopia, and a history of retinal detachment in the opposite eye.

The procedure for the treatment of CMV retinitis is similar to other retinal detachment repairs. The treatment procedure may include scleral buckling, laser, and pneumatic retinopexy. Nonetheless, the highest success rates in reattachment appear to be with vitrectomy, laser, and silicone oil to push the retina flat against the outer wall of 
the eye [24]. Luckily, due to the medical management of patients with AIDS the prevalence of CMV retinitis is declining [24].

In addition, a patient with severe eye trauma may require vitreoretinal surgery. Severe eye trauma can result in vitreous hemorrhage which can be accompanied by significant retinal damage. A vitrectomy procedure is the most common procedure after severe eye trauma. The vitrectomy procedure is performed after initial wound repair, active bleeding subsides, and the cornea is clear [22]. However, it is also important that a vitrectomy is performed in a timely manner before further retinal detachment occurs.

One additional reason for vitreoretinal surgery is due to the complications of cataract surgery. Approximately two percent of cataract surgery patients develop rhegmatogenous retinal detachment [22]. It is thought that the retinal detachment is related to anterior movement of the vitreous during or after the cataract surgery. Furthermore, vitreous loss is said to occur after one percent of cataract surgeries, however, there is recent evidence that suggests the incidence may be closer to five percent [22]. If a capsule rupture occurs during cataract surgery it is possible lens material or the entire lens can be displaced into the vitreous. A vitrectomy procedure along with phacofragmentation is very effective in removing posterior lens material.

There are numerous other diseases and reasons for which vitreoretinal surgery can be required. Vitreoretinal surgeons are experts in determining if vitreoretinal surgery is required and the best procedure to follow.

Even though there has been a vast amount of advancements in vitreoretinal surgeries in recent years complications still arise with vitreoretinal surgery. Postoperative elevated intraocular pressure, cataract formation, and endophthalmitis are 
complications that can occur after intraocular surgeries, including vitreoretinal surgery [50]. In addition, there are complications that are specific to vitreoretinal surgery. These complications include [50]:

- Retrobulbar anesthesia complications

- Suprachoroidal hemorrhage

- Iatrogenic phototoxicity

- Nitrous oxide

- Air-fluid Exchange complications

- Retained perfluorocarbon liquid

- Sympathetic ophthalmia

- Wound leakage complications

- Aminoglycoside toxicity

There are many vitreoretinal diseases that were previously untreatable that now be managed through the advancements in vitreoretinal surgery. Vitreoretinal surgery is a widely used ophthalmic surgical procedure where many ophthalmologists are focusing their attention in order to enhance and restore vision in many individuals. 


\section{APPENDIX III:}

\section{Failure Mode and Effects Analysis}


A Failure Mode and Effect Analysis, or FMEA, is and engineering technique used to define, identify, and eliminate known and/or potential failures, problems, and errors from the system, design, process, and/or service before they reach the customer [52]. If a FMEA is conducted properly and appropriately and the necessary mitigations are put in place the potential for risk in the system, design, process, and service will be significantly reduced.

In the mid-1960s the first formal FMEA was conducted in the aerospace industry and specifically looked at safety issues [41]. The purpose and focus of the first FMEA was to look at safety issues with the goal of preventing safety accidents and incidents from occurring. Even though engineers have always analyzed processes and products for potential failures FMEA standards have become well known. The concept of a FMEA standardizes the approach and establishes a common language that can be used within and between companies.

The main reason FMEAs gained widespread appeal outside of looking only at safety issues was largely due to the automotive industry and the supplier requirements. The automotive industry requires its suppliers to conduct design and process FMEAs with the goal of eliminating failures before they occur. Today a FMEA is a common and well known tool used in all engineering disciplines.

Even though there is a wide variety of applications for FMEAs and they can be performed slightly different the overall concept is the same. A FMEA is a common engineering approach to error analysis where the likelihood of a particular process failure is combined with an estimate of the relative impact of that error. From this a criticality index is produced. The prioritization of specific processes as quality improvement 
targets are produced when the probability of failure is combined with the consequences of failure. Simply stated, a Failure Mode and Effects Analysis can be used on products, devices, systems, or process to establish the risks, rank their order of importance and help determine any mitigation that is required.

A FMEA process is usually considered to be part of the quality system. This ensures that systems are in place to enhance and support FMEAs. Even though a FMEA can be a benefit if it is not part of a quality system when there are systems in place to support and enhance a FMEA there are additional advantages. A FMEA is a very valuable part to a comprehensive quality system.

In order for a FMEA to be successfully completed there are several quality system elements that must be understood. Some of the key quality system elements to a FMEA can be seen in Table 3. Even though there can be one individual that leads a FMEA process the process is most successful when there is input from all individuals who have a role in the process. 


\begin{tabular}{|l|l|}
\hline Quality System Element & Role in the FMEA Process \\
\hline Leadership & $\begin{array}{l}\text { Supports the FMEA process assuring the FMEA team } \\
\text { has the necessary tools, resources, and time to work on } \\
\text { the FMEA. }\end{array}$ \\
\hline Strategic Quality Planning & $\begin{array}{l}\text { Uses the results of FMEAs to assist in directing future } \\
\text { improvement activities. }\end{array}$ \\
\hline $\begin{array}{l}\text { Process and Business } \\
\text { Measures }\end{array}$ & $\begin{array}{l}\text { Measures and monitors the results of FMEAs both in } \\
\text { terms of product quality and bottom line results. }\end{array}$ \\
\hline $\begin{array}{l}\text { Effective use of Data and } \\
\text { Information }\end{array}$ & $\begin{array}{l}\text { Provides facts and data to confirm FMEA analysis and to } \\
\text { measure the results of the FEMA process. }\end{array}$ \\
\hline $\begin{array}{l}\text { Process Control (both the } \\
\text { company's and the suppliers') }\end{array}$ & $\begin{array}{l}\text { Assures a stable process and product at the start of an } \\
\text { FMEA and statistically monitors improvements made } \\
\text { through the FMEA process. }\end{array}$ \\
\hline Human Resources & $\begin{array}{l}\text { Supports the FMEA team with appropriate training in } \\
\text { quality improvement tools and techniques. }\end{array}$ \\
\hline Training & $\begin{array}{l}\text { Provides the basic skills necessary to work on an FMEA } \\
\text { team, identify potential problems, and determine } \\
\text { solutions. }\end{array}$ \\
\hline A Documented Quality Plan & $\begin{array}{l}\text { Identifies FMEAs as part of the overall quality strategy } \\
\text { of the company. Defines when and where FMEAs } \\
\text { should be sued and documents the FMEA process the } \\
\text { FMEA teams should use. }\end{array}$ \\
\hline Documented Procedures & $\begin{array}{l}\text { Assure that consistent operating methods are being used } \\
\text { thus reducing unnecessary variation in the process and } \\
\text { product. }\end{array}$ \\
\hline Design Control & Assures consistency in the design process. \\
\hline Customer Focus & $\begin{array}{l}\text { Provides the team with information about what's } \\
\text { important to the customer and information that can be } \\
\text { incorporated in the FMEA process. }\end{array}$ \\
\hline A Customer Feedback System & $\begin{array}{l}\text { Provides the FMEA team with additional data to } \\
\text { consider during the FMEA process. }\end{array}$ \\
\hline Tab3: &
\end{tabular}

Table 3: The twelve key elements of the FMEA process [41]

It would be extremely difficult for one individual to perform a Failure Mode and Effects Analysis on his or her own without input and suggestions from others. A FMEA is a team-based methodology for identifying potential problems with both new and existing designs [52]. Usually a FMEA is best done as a team effort to see the different ways individuals think and to be sure to look at potential failure modes from all perspectives. 
To complete a FMEA successfully it is important that the team knows the processes and supporting technologies that influence the system. Furthermore, in order to make sure that the best results are obtained from an FMEA there must be reliable data on the product or process. Without reliable data the FMEA can be based on guesswork and opinions rather than facts. It is very easy for an FMEA team to focus on wrong failure modes, which in turn leads for opportunities for improvement to be missed.

In addition, when completing an FMEA it is extremely important that the scope of the task is well defined. It is important that everyone involved in the FMEA process understands the scope of the project so the focus is on the correct aspects of the process or product. If the scope of the FMEA is not clearly defined and understood by all individuals giving input to the project there is the potential the wrong aspect of the product or process will be of focus. If there is a large process it is best to break the FMEA into smaller sub-process and perform a FMEA on each smaller aspect. If potential failure modes of smaller portions of a process are noted it is less likely that there will be critical failure modes overlooked.

There are many variations and format styles to a FMEA. However, they all strive at accomplishing three things [52].

1. Predicting what failures could occur

2. Predicting the effect of the failure

3. Establishing steps that might be taken to prevent the failure, or its effect on the function

Even though the FMEA process is very time consuming and takes a great deal of resources it is a beneficial tool to use because it is a powerful and proactive engineering 
quality method that helps identify and counter weak points. The benefits that are obtained from FMEA are far greater that the time and resources that it takes to execute the analysis. The main reasons to complete a Failure Mode and Effect Analysis include identifying the inadequacies in the development of the product, regulatory reasons, continuous improvement, preventive approach, team building, and requirement of procedures.

When a Failure Mode and Effect Analysis is completed properly it has the potential of reducing the likelihood of customer complaints, reducing maintenance and warranty costs, reducing the possibility of safety failures, reducing the possibility of extended life or reliability failures, and reducing the likelihood of product liability claims. One other benefit to a FMEA is that it can be used and understood by individuals with all ranges of technical levels. Even though complicated statistics are not involved in completing a FMEA there is the potential of yielding significant saving for a company as well as reducing the potential costly liability of a process or products that does not perform as was promised.

The greatest benefits from a FMEA will come if it is conducted in the products design or process development stages. The earlier an FMEA can be completed the more easily issues can be resolved in a timely fashion with fewer issues. The earlier missing controls to prevent and detect failures and to highlight failure modes impacting the end user can be identified the less likely there is for problems to arise in the future. If a FMEA is completed early in the design process it is likely that product and process improvements can be made with relatively easy and inexpensive changes. Reducing or eliminating late changes and corrective actions will be a benefit not only in terms of cost 
but also in the resources that are required. However, there also can be significant benefits if a FMEA is conducted on existing products and processes.

There are two main focuses behind a FMEA. A FMEA can be focused on the product or the process. "The object for a product or design FMEA is to uncover problems with the product that will result in safety hazards, product malfunctions, or a shortened product life" [41].

Furthermore, an assembly process FEMA is an extremely important step that must be completed before a product can be released into the market. The goal of a process FMEA is to uncover problems that are related to the manufacture of the product. An assembly process FMEA includes identifying and correcting customer safety risks, identifying other special risks such as regulatory and key performance risks, assuring consistency in assembly, and maximizing product quality. In addition, reducing customer complaints, reducing field service costs, ensuring optimal prevention or detection process controls are in place, and prioritizing process improvement actions are all included in an assembly FMEA. Many times for a complex assembly process the FMEA is organized into small sub-modules FMEAs which together make a complete assembly FMEA. When the process is broken down into logical units for evaluation the FMEA is the most valuable. During any phase of the design process a product FMEA can be completed whether it is preliminary design, prototype, and final design in addition to products that are already in production.

The focus of a process FMEA is on the process reliability and resulting product quality. The primary customer for this FMEA is the end-product user. When completing a process FMEA it is helpful to think in terms of the elements of a process which are 
people materials, equipment, methods, and environment. Based on the type of FMEA the rating scales may have to be slightly modified to fit the specific characteristics of the product or process.

The FMEA procedure is very different than a Fault Tree Analysis. A Fault Tree Analysis is a top-down process where the function is decomposed into all of its parts whereas an FMEA starts with the required function. When the required functions are identified the components to provide the functions are identified and then for each component the possible modes of failure are identified.

Completing a FMEA correctly is a lengthy and time consuming process. Involved in the FMEA task is teamwork and brainstorming, along with documentation and engineering evaluation. The FMEA process can be broken up into several steps as a guideline. The following are ten suggested steps for performing a FMEA [41].

Step 1: Review the Process

Step 2: Brainstorm Potential Failure Modes

Step 3: List Potential Effects of Each Failure Mode

Step 4: Assign a Severity Rating for Each Effect

Step 5: Assign an Occurrence Rating for Each Failure Mode

Step 6: Assign a Detection Rating for Each Failure Mode and/or Effect

Step 7: Calculate the Risk Priority Number for Each Failure Mode

Step 8: Prioritize the Failure Modes for Action

Step 9: Take Action to Eliminate or Reduce the High-Risk Failure Modes

Step 10: Calculate the Resulting RPN as the Failure Modes are Reduced 
For a Failure Mode and Effect Analysis to be successful good documentation procedures are required. It is important that any potential mode considered is documented even if it is thought to be insignificant. All companies completing FMEAs have their own format and procedures for completing a FMEA. There is no configuration for a FMEA that is well defined other than it is usually in a spreadsheet format. However, there are several important items to include in a FMEA. These include, but are not necessarily limited to:

- Product, part number, process or system

- Core team

- Equipment element and functions

- Potential failure mode

- Potential effects of failure

- Severity rating

- Potential causes/mechanisms of failure

- Process controls preventing the failure

- Occurrence rating

- Process controls detecting the failure

- Detection rating

- Risk priority number

- Actions

- Mitigated severity, occurrence, and detection for new risk priority number 
Shown in Table 4 is a sample FMEA table. The tables can vary widely, but this sample table includes some of the general characteristics and important items to include in a FMEA.

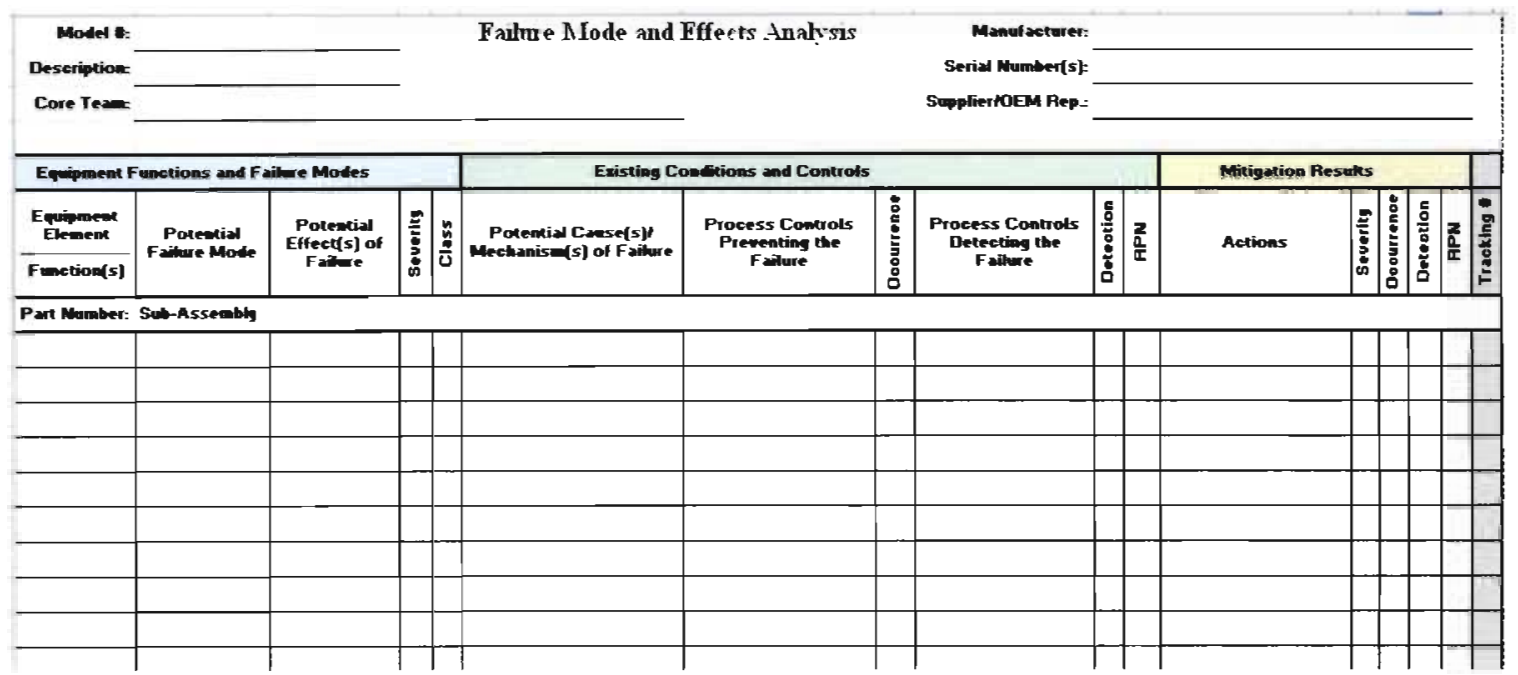

Table 4: The layout of a sample FMEA table [46]

In order to determine the potential failure modes there are several questions that can be asked about the components and their functions. In order to make sure all of the necessary considerations are included in the FMEA the team needs to have a very clear understanding of how the system works as a whole unit and all of the functions of each individual part. Some of the questions about the functions can include [28]. What if the function fails to occur at the right time?

- What if the function fails to occur in the proper sequence?

- What if this function fails to occur completely?

After understanding the failures have been identified the consequences can be determined and the potential failure modes can be listed in the FMEA. 
The term failure has a distinct definition when talking about an FMEA. The term failure does not mean the actual catastrophic material breakage or failure, but rather the inability to meet a customer's requirements and needs.

The potential failure mode column lists the manner in which the assembly process could go incorrectly or which the item could potentially fail to meet the process output requirements and/or design intent as described in the function/requirements section of the FMEA form. The potential impact of the failure mode to the system performance or end user is described in the potential effects of the failure column. It is in this column where the effects on subsequent operations and end user are described given that the failure mode already occurred. The consequences of the failure can be local to a particular component or the effects can extend to sub-assemblies and to the total system. The potential effects are described in terms of what the customer actually notices or experiences.

Furthermore, the severity is a rating of the importance of the potential effects. The scale of severity rating is on a scale of one to ten, where ten represents the most severe risks. Shown in Tables 5 and 6 are example tables for the determination of the severity rating. 


\begin{tabular}{|c|c|c|c|}
\hline Effect & \multicolumn{2}{|c|}{ Customer Impact -or- Manufacturing Impact } & Rating \\
\hline $\begin{array}{l}\text { Hazardous } \\
\text { without } \\
\text { warning }\end{array}$ & $\begin{array}{l}\text { Very high severity ranking when a } \\
\text { potential failure mode affects safety } \\
\text { of product user, patient, and/or } \\
\text { involves noncompliance with } \\
\text { government regulation without } \\
\text { warning. }\end{array}$ & $\begin{array}{l}\text { May endanger operator (machine or } \\
\text { assembly) without warning }\end{array}$ & 10 \\
\hline $\begin{array}{l}\text { Hazardous } \\
\text { with } \\
\text { warning }\end{array}$ & $\begin{array}{l}\text { Very high severity ranking when a } \\
\text { potential failure mode affects safe } \\
\text { use or product and/or involves } \\
\text { noncompliance with government } \\
\text { regulation with warning. }\end{array}$ & $\begin{array}{l}\text { May endanger operator (machine or } \\
\text { assembly) with warning. }\end{array}$ & 9 \\
\hline Very high & $\begin{array}{l}\text { Product not usable (loss of primary } \\
\text { function). }\end{array}$ & $\begin{array}{l}100 \% \text { of product may have to be } \\
\text { scrapped, or repaired with a } \\
\text { significant internal failure cost } \\
\text { incurred. }\end{array}$ & 8 \\
\hline High & $\begin{array}{l}\text { Product functions at a reduced level } \\
\text { of performance. Customer very } \\
\text { dissatisfied. }\end{array}$ & $\begin{array}{l}\text { Product may have to be sorted and a } \\
\text { portion scrapped, or repaired with } \\
\text { moderate internal failure cost } \\
\text { incurred. }\end{array}$ & 7 \\
\hline Moderate & $\begin{array}{l}\text { Product functional but convenience } \\
\text { features inoperable. Customer } \\
\text { dissatisfied. }\end{array}$ & $\begin{array}{l}\text { A portion of the product may have to } \\
\text { be scrapped with no sorting, or can be } \\
\text { repaired at a low cost. }\end{array}$ & 6 \\
\hline Low & $\begin{array}{l}\text { Product functional but convenience } \\
\text { item(s) operate at a reduced level of } \\
\text { performance. Customer somewhat } \\
\text { dissatisfied. }\end{array}$ & $\begin{array}{l}100 \% \text { of product may have to be } \\
\text { reworked, but it may be done } \\
\text { conveniently by the assembly line } \\
\text { during normal operations. }\end{array}$ & 5 \\
\hline Very low & $\begin{array}{l}\text { Fit \& finish or other cosmetic item } \\
\text { does not conform. Defect noticed by } \\
\text { most customers (greater than } 75 \% \text { ). }\end{array}$ & $\begin{array}{l}\text { Product may have to be sorted, with } \\
\text { no scrap and a portion reworked. }\end{array}$ & 4 \\
\hline Minor & $\begin{array}{l}\text { Fit \& finish or other cosmetic item } \\
\text { does not conform. Defect noticed by } \\
50 \text { percent of customers. }\end{array}$ & $\begin{array}{l}\text { A portion of the product may have to } \\
\text { be reworked, with no scrap on-line. }\end{array}$ & 3 \\
\hline Very minor & $\begin{array}{l}\text { Fit \& finish or other cosmetic item } \\
\text { does not conform. Defect noticed by } \\
\text { discriminating customers (less than } \\
25 \text { percent). }\end{array}$ & $\begin{array}{l}\text { Operators need to be sorting or } \\
\text { repairing during production to reduce } \\
\text { frequency, but no other provisions are } \\
\text { needed. }\end{array}$ & 2 \\
\hline None & No discernible effect. & $\begin{array}{l}\text { Or slight inconvenience to operation } \\
\text { or operator, or no effect. }\end{array}$ & 1 \\
\hline
\end{tabular}

Table 5: The ratings for the severity of a potential failure mode [46] 


\begin{tabular}{|l|l|l|}
\hline Severity process and/or service guidelines & \multicolumn{1}{|c|}{} \\
\hline Rank & $\begin{array}{l}\text { Minor: Unreasonable to expect that the minor nature } \\
\text { of this failure would cause any real effect on the } \\
\text { product and/or service. Customer will probably not } \\
\text { even notice the failure. }\end{array}$ & $\begin{array}{l}\text { Unreasonable to expect that the minor } \\
\text { nature of the failure would cause any } \\
\text { noticeable effect on the product and/or the } \\
\text { service. Customer most likely will not be } \\
\text { able to detect the failure. }\end{array}$ \\
\hline 1 & $\begin{array}{l}\text { Low: Low severity ranking due to nature of failure } \\
\text { causing only a slight customer annoyance. Customer } \\
\text { probably will notice a slight deterioration of the } \\
\text { product and/or service, a slight inconvenience in the } \\
\text { next process, or minor rework action. }\end{array}$ & $\begin{array}{l}\text { Low severity ranking due to a slight } \\
\text { annoyance of the failure. Customer } \\
\text { probably will notice a very minor } \\
\text { deterioration of the product and/or service. }\end{array}$ \\
\hline $4-6$ & $\begin{array}{l}\text { Moderate: Moderate ranking because failure causes } \\
\text { some dissatisfaction. Customer is made } \\
\text { uncomfortable or is annoyed by the failure. May } \\
\text { cause the use of unscheduled repairs and/or damage } \\
\text { to equipment. }\end{array}$ & $\begin{array}{l}\text { Moderate failure causes customer } \\
\text { dissatisfaction. Customer is made } \\
\text { uncomfortable and/or is annoyed by the } \\
\text { failure. Some degradation of performance } \\
\text { is noticeable. }\end{array}$ \\
\hline $7-8$ & $\begin{array}{l}\text { High: High degree of customer dissatisfaction due to } \\
\text { the nature of the failure such as an inoperable } \\
\text { product or inoperative convenience. Does not } \\
\text { involve safety issues or government regulations. } \\
\text { May cause disruptions to subsequent processes } \\
\text { and/or services. }\end{array}$ & $\begin{array}{l}\text { High degree of customer dissatisfaction due } \\
\text { to the nature of the failure. No safety or } \\
\text { government regulations issues. }\end{array}$ \\
\hline $9-10$ & $\begin{array}{l}\text { Very High: Very high severity is when the failure } \\
\text { affects safety and involves noncompliance with } \\
\text { government regulations. }\end{array}$ & $\begin{array}{l}\text { Very high severity ranking when safety } \\
\text { issues are involved or compliance to } \\
\text { government regulations is ignored }\end{array}$ \\
\hline
\end{tabular}

Table 6: Guidelines for severity rankings for a process and/or service FMEA [52]

The next column on the FMEA spreadsheet next to the severity column is the class column. The class column is an optional column that can be filled out where special codes are input to delineate situations that must absolutely be addressed regardless of ratings. Three examples of codes that can be used are "R" for regulatory requirements, "S" for safety concerns, "M" for other mandatory product or performance requirements

Next, the potential root cause for a failure mode is described in the potential cause column of the FMEA table. The potential cause is the mechanism or condition that results in the failure mode, and is typically described in terms of something that can be corrected, flagged, prevented, or otherwise controlled. In addition, any preventative controls that are in place are recorded in process controls preventing the failure column. When trying to determine root causes many times why-why diagrams are helpful. 
The occurrence column describes how likely each cause is based upon the underlying equipment and process along with the effectiveness of the prevention controls listed. It can also be termed "likelihood" or "frequency". The ratings for the occurrence use a relative scale from 1 to 10 where 10 being the most frequent. The probabilities that are given are an approximation. The probabilities depend on characteristics such as the nature of the failure, the robustness of the design, and the level of quality developed in manufacturing. Shown in Tables 7 and 8 are guidelines for determining the occurrence rating.

\begin{tabular}{|l|l|c|}
\hline \multicolumn{1}{|c|}{ Description } & \multicolumn{1}{c|}{ Likely Failure Rate } & Rating \\
\hline $\begin{array}{l}\text { Very High: Failure almost } \\
\text { inevitable }\end{array}$ & $>1$ in 2 pieces processed & 10 \\
\cline { 2 - 3 } $\begin{array}{l}\text { High: Generally similar to } \\
\text { previous process that have often } \\
\text { failed }\end{array}$ & 1 per 3 pieces processed & 9 \\
\hline $\begin{array}{l}\text { Moderate: Generally associated } \\
\text { with processes similar to previous } \\
\text { process that have occasionally } \\
\text { failed }\end{array}$ & 1 per 80 pieces processed & 7 \\
\cline { 2 - 3 } $\begin{array}{l}\text { Low: Only isolated failures have } \\
\text { occurred with similar or identical } \\
\text { processes }\end{array}$ & 1 per 2,000 pieces processed & 6 \\
\hline $\begin{array}{l}\text { Remote: Failure unlikely. No } \\
\text { failures associated with similar or } \\
\text { identical processes. }\end{array}$ & $<1$ per 500,000 pieces processed & 5 \\
\hline
\end{tabular}

Table 7: The description for the occurrence ratings for a potential failure mode [46] 


\begin{tabular}{|c|c|c|c|}
\hline \multicolumn{4}{|c|}{ Occurrence process and/or service guidelines } \\
\hline Rank & & Rank & \\
\hline 1 & $\begin{array}{l}\text { Remote probability of occurrence. } \\
\text { Capability shows at least } X-b a r+/-3 \sigma \\
\text { within specifications }(1 / 10,000) \text {. }\end{array}$ & 1 & $\begin{array}{l}\text { Failure is unlikely. } \mathrm{C}_{\mathrm{pk}} \text { greater or equal to } \\
1.67\left(<1 \text { in } 10^{\wedge} 6 \text { or } \sim+/-5 \sigma\right) .\end{array}$ \\
\hline $2-5$ & $\begin{array}{l}\text { Low probability of occurrence. Process } \\
\text { in statistical control. Capability shows at } \\
\text { least } X-\text { bar }+/-3 \sigma \text { within specifications } \\
(1 / 5,000-1 / 500) \text {. }\end{array}$ & 2 & $\begin{array}{l}\text { Very low: Process is in statistical control. } \\
\text { Isolated failures exist. } C_{p k} \text { greater or equal to } \\
1.33(1 \text { in } 20,000 \text { or } \sim+/-4 \sigma) \text {. }\end{array}$ \\
\hline $6-7$ & $\begin{array}{l}\text { Moderate probability of occurrence. } \\
\text { Process in statistical control with } \\
\text { occasional failures, but not in major } \\
\text { proportions. Capability shows at least X- } \\
\text { bar }+/-2.5 \sigma \text { within specifications }(1 / 20- \\
1 / 200) \text {. }\end{array}$ & 3 & $\begin{array}{l}\text { Low: Process in statistical control. Isolated } \\
\text { failures occur sometimes. } C_{\mathrm{pk}} \text { greater or equal } \\
\text { to } 1.00(1 \text { in } 4,000 \text { or } \sim+/-3.5 \sigma) \text {. }\end{array}$ \\
\hline $8-9$ & $\begin{array}{l}\text { High probability of occurrence. Process } \\
\text { in statistical control with failures often } \\
\text { occurring. Capability shows X-bar }+/- \\
1.5 \sigma(1 / 100-1 / 20) \text {. }\end{array}$ & $4-6$ & $\begin{array}{l}\text { Moderate: Process in statistical control with } \\
\text { occasional failures but not in major } \\
\text { proportions. } \mathrm{C}_{\mathrm{pk}} \text { is less or equal to } 1.00 \text { ( } 1 \text { in } \\
1,000 \text { to } 1 \text { in } 80 \text { or } \sim+/-3 \sigma \text { ). }\end{array}$ \\
\hline \multirow[t]{2}{*}{10} & $\begin{array}{l}\text { Very high probability of occurrence. } \\
\text { Failure is almost certain. }(1 / 10+) .\end{array}$ & $7-8$ & $\begin{array}{l}\text { High: Process not in statistical control. Have } \\
\text { failures often }(1 / 40 \text { to } 1 / 20) \text {. }\end{array}$ \\
\hline & & $9-10$ & Very High: Failures are inevitable. \\
\hline
\end{tabular}

Table 8: Guidelines for occurrence rankings for a process and/or service FMEA [52]

The next determination for a potential failure mode that must be made is the process controls detecting the failure. The process controls detecting the failure are the current controls in place that may identify problems and lead to corrective action to take place before there is a customer impact. Some common examples of how the potential failure might be detected are a design checklist, a specific design calculation, a visual quality inspection, alarms, operator observation, and testing. A good example of a process control detecting the failure for a new medical device is a Manufacturing Test Procedure or MTP.

Subsequently, the detection rating is determined. The ability to catch defects given the potential cause has occurred using the detective controls previously identified is rated on a scale from one to ten. This is the detection rating and sample guidelines are shown in Tables 9 and 10. A ranking of a ten is the worst case scenario indicating that the failure mode has no chance of being detected. It is important to understand that the 
detection is a measure of the probability that a given root cause will be detected and

corrected in design or manufacturing before the product is delivered to the customer.

Therefore, the detection ranking depends highly on the quality review systems that are in

place where the product is being manufactured.

\begin{tabular}{|c|c|c|c|c|c|c|}
\hline \multirow[t]{2}{*}{ Detection } & \multirow[t]{2}{*}{ Criteria } & \multicolumn{3}{|c|}{ Control Type } & \multirow[t]{2}{*}{ Examples of Detection Methods } & \multirow[t]{2}{*}{ Rank } \\
\hline & & 突 & 点 & 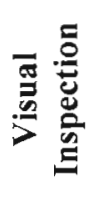 & & \\
\hline Impossible & $\begin{array}{l}\text { No detection is } \\
\text { possible }\end{array}$ & & & & Cannot detect or is not checked & 10 \\
\hline Very remote & $\begin{array}{l}\text { Controls very } \\
\text { unlikely to detect }\end{array}$ & & & $X$ & $\begin{array}{l}\text { Control is achieved with indirect or } \\
\text { random checks only }\end{array}$ & 9 \\
\hline Remote & $\begin{array}{l}\text { Controls have a } \\
\text { poor chance of } \\
\text { detection }\end{array}$ & & & $\mathrm{X}$ & $\begin{array}{l}\text { Control is achieved with } 100 \% \text { visual } \\
\text { inspection }\end{array}$ & 8 \\
\hline Very low & $\begin{array}{l}\text { Controls have a } \\
\text { poor chance of } \\
\text { detection }\end{array}$ & & & $\mathrm{X}$ & $\begin{array}{l}\text { Control is achieved with } 100 \% \text { visual } \\
\text { inspection with certified operators and/or } \\
\text { supplemental inspection }\end{array}$ & 7 \\
\hline Low & $\begin{array}{l}\text { Controls may } \\
\text { detect }\end{array}$ & & $\mathrm{X}$ & & $\begin{array}{l}\text { Control is achieved with charting } \\
\text { methods, such as SPC }\end{array}$ & 6 \\
\hline Moderate & $\begin{array}{l}\text { Controls may } \\
\text { detect }\end{array}$ & & $\mathrm{X}$ & & $\begin{array}{l}\text { Control is based on variable gauging after } \\
\text { parts have left the station or attribute } \\
\text { gauging performed on } 100 \% \text { of } \\
\text { components after parts have left the } \\
\text { station. }\end{array}$ & 5 \\
\hline $\begin{array}{l}\text { Moderately } \\
\text { High }\end{array}$ & $\begin{array}{l}\text { Controls have a } \\
\text { good chance of } \\
\text { detection }\end{array}$ & & $X$ & & $\begin{array}{l}\text { Error detection in subsequent operations, } \\
\text { or gauging performed on setup and furst- } \\
\text { piece check (for setup causes only) }\end{array}$ & 4 \\
\hline High & $\begin{array}{l}\text { Controls have a } \\
\text { good chance of } \\
\text { detection }\end{array}$ & $\mathrm{X}$ & & & $\begin{array}{l}\text { Error detection in-station or error } \\
\text { detection in subsequent operations by } \\
\text { multiple layers of acceptance: supply } \\
\text { select, install, verify. Cannot accept } \\
\text { discrepant part. }\end{array}$ & 3 \\
\hline Very High & $\begin{array}{l}\text { Controls almost } \\
\text { certain to detect }\end{array}$ & $\mathrm{X}$ & & & $\begin{array}{l}\text { Error detection in-station (automatic } \\
\text { gauging with stop feature). Cannot pass } \\
\text { discrepant component. }\end{array}$ & 2 \\
\hline Certain & $\begin{array}{l}\text { Controls almost } \\
\text { certain to detect }\end{array}$ & $\mathrm{X}$ & & & $\begin{array}{l}\text { Discrepant parts cannot be made because } \\
\text { item has been error-proofed by process, } \\
\text { product, or equipment design. }\end{array}$ & 1 \\
\hline
\end{tabular}

Table 9: The criteria for the ratings of the diction for a potential failure mode [46] 


\begin{tabular}{|l|l|l|}
\hline \multicolumn{2}{|l|}{ Detection process and/or service guidelines } \\
\hline Rank & $\begin{array}{l}\text { Very high: Controls almost certainly } \\
\text { will detect the existence of a defect. }\end{array}$ & $\begin{array}{l}\text { Remote likelihood that the product or service will be } \\
\text { delivered }(1 / 10,000) \text {. The defect is functionally } \\
\text { obvious and readily detected. Detection reliability at } \\
\text { least } 99.99 \text { percent. }\end{array}$ \\
\hline $\mathbf{2 - 5}$ & $\begin{array}{l}\text { High: Controls have a good chance of } \\
\text { detecting the existence of a failure. }\end{array}$ & $\begin{array}{l}\text { Low likelihood that the product would be delivered } \\
\text { with the defect. The defect is obvious }(1 / 5,000-1 / 500) . \\
\text { Detection reliability at least } 99.80 \text { percent. }\end{array}$ \\
\hline $6-8$ & $\begin{array}{l}\text { Moderate: Controls may detect the } \\
\text { existence of a defect. }\end{array}$ & $\begin{array}{l}\text { Moderate likelihood that the product will be delivered } \\
\text { with the defect. The defect is easily identified (1/200- } \\
\text { l/50). Detection reliability at least } 98.00 \text { percent. }\end{array}$ \\
\hline 9 & $\begin{array}{l}\text { Low: Controls more likely will not } \\
\text { detect the existence of a defect. }\end{array}$ & $\begin{array}{l}\text { High likelihood that the product would be delivered } \\
\text { with the defect. The defect is subtle (1/20). Detection } \\
\text { reliability greater than } 90 \text { percent. }\end{array}$ \\
\hline 10 & $\begin{array}{l}\text { Very low: Controls very likely will not } \\
\text { detect the existence of a defect. }\end{array}$ & $\begin{array}{l}\text { Very high likelihood that the product and/or service } \\
\text { will be delivered with the defect. Item is usually not } \\
\text { checked or not checkable. Quite often the defect is } \\
\text { latent and would not appear during the process or } \\
\text { service (1/10+). Detection reliability } 90 \text { percent or } \\
\text { less. }\end{array}$ \\
\hline
\end{tabular}

Table 10: Guidelines for detection rankings for a process and/or service FMEA [52]

It is important to note that the guidelines provided for the severity, occurrence, and detection ratings are suggestions and may be changed to reflect specific situations. After the severity, occurrence, and detection numbers are all determined they are multiplied together to obtain the risk priority number or RPN.

$$
\begin{gathered}
\text { Risk Priority Number }(R P N)= \\
\text { (severity of failure) } x \text { (occurrence of failure) } x \text { (detection rating) }
\end{gathered}
$$

From the RPN the necessary mitigations can be determined. It can be seen that the RPN can vary between values of 1 and 1000. A threshold limit is set which states the value that any RPN above must require some type of mitigation. It is common that any RPN with a value of over 100 requires some type of mitigation take place.

After the risk priority numbers are determined they can be prioritized and corrective action can begin to remove a potential design, manufacturing, or operational failure. The RPN numbers can be prioritized based on their values. Therefore, the potential failure mode with the highest risk priority number would be the first for a 
mitigation to be put in place. Another technique to determine what potential failure modes require mitigation is to place the risk priority numbers in order and perform a Pareto analysis.

After the mitigation has been implemented the potential failure mode is given new severity, occurrence, and detection numbers to determine a revised risk priority number ensuring that it is less than 100 . Therefore, in order for a FMEA to be complete the final risk priority numbers are all less than 100 meaning the necessary mitigations were put in place all potential failure modes have been addressed and there is minimal risk associated with the product or process. 


\section{APPENDIX IV:}

\section{NGVS Fluidics Sub-Module}

Failure Mode and Effects Analysis 
This Appendix was intentionally left blank due to proprietary information. 